\title{
Article
}

Subscriber access provided by University of East Anglia Library

\section{Dendritic Carbene Metal Carbazole Complexes as Photo-Emitters for Fully Solution-Processed OLEDs}

Alexander S. Romanov, Le Yang, Saul T. E. Jones, Dawei Di, Olivia J. Morley, Bluebell H. Drummond, Antti P. M. Reponen, Mikko Linnolahti, Dan Credgington, and Manfred Bochmann

Chem. Mater., Just Accepted Manuscript • DOI: 10.1021/acs.chemmater.8b05112 • Publication Date (Web): 26 Apr 2019

Downloaded from http://pubs.acs.org on April 29, 2019

\section{Just Accepted}

"Just Accepted" manuscripts have been peer-reviewed and accepted for publication. They are posted online prior to technical editing, formatting for publication and author proofing. The American Chemical Society provides "Just Accepted" as a service to the research community to expedite the dissemination of scientific material as soon as possible after acceptance. "Just Accepted" manuscripts appear in full in PDF format accompanied by an HTML abstract. "Just Accepted" manuscripts have been fully peer reviewed, but should not be considered the official version of record. They are citable by the Digital Object Identifier (DOI®). "Just Accepted" is an optional service offered to authors. Therefore, the "Just Accepted" Web site may not include all articles that will be published in the journal. After a manuscript is technically edited and formatted, it will be removed from the "Just Accepted" Web site and published as an ASAP article. Note that technical editing may introduce minor changes to the manuscript text and/or graphics which could affect content, and all legal disclaimers and ethical guidelines that apply to the journal pertain. ACS cannot be held responsible for errors or consequences arising from the use of information contained in these "Just Accepted" manuscripts. 


\title{
Dendritic Carbene Metal Carbazole Complexes as Photo-Emitters for Fully Solution- Processed OLEDs
}

Alexander S. Romanov, ${ }^{* \dagger}$ Le Yang, ${ }^{*}, \|$ Saul T. E. Jones, ${ }^{\ddagger}$ Dawei Di, ${ }^{\ddagger}$ Olivia J. Morley, Bluebell H. Drummond, * Antti P. M. Reponen, ${ }^{*}$ Mikko Linnolahti, ${ }^{*}$ Dan Credgington** and Manfred Bochmann*†

† School of Chemistry, University of East Anglia, Earlham Road, Norwich, NR4 7TJ, UK;

$¥$ Department of Physics, Cavendish Laboratory, Cambridge University, Cambridge CB3 0HF, UK

$\S$ Department of Chemistry, University of Eastern Finland, Joensuu Campus, FI-80101 Joensuu, Finland "Institute of Materials Research and Engineering (IMRE), A*STAR, 2 Fusionopolis Way, Singapore 138634

\section{TABLE OF CONTENTS ENTRY}
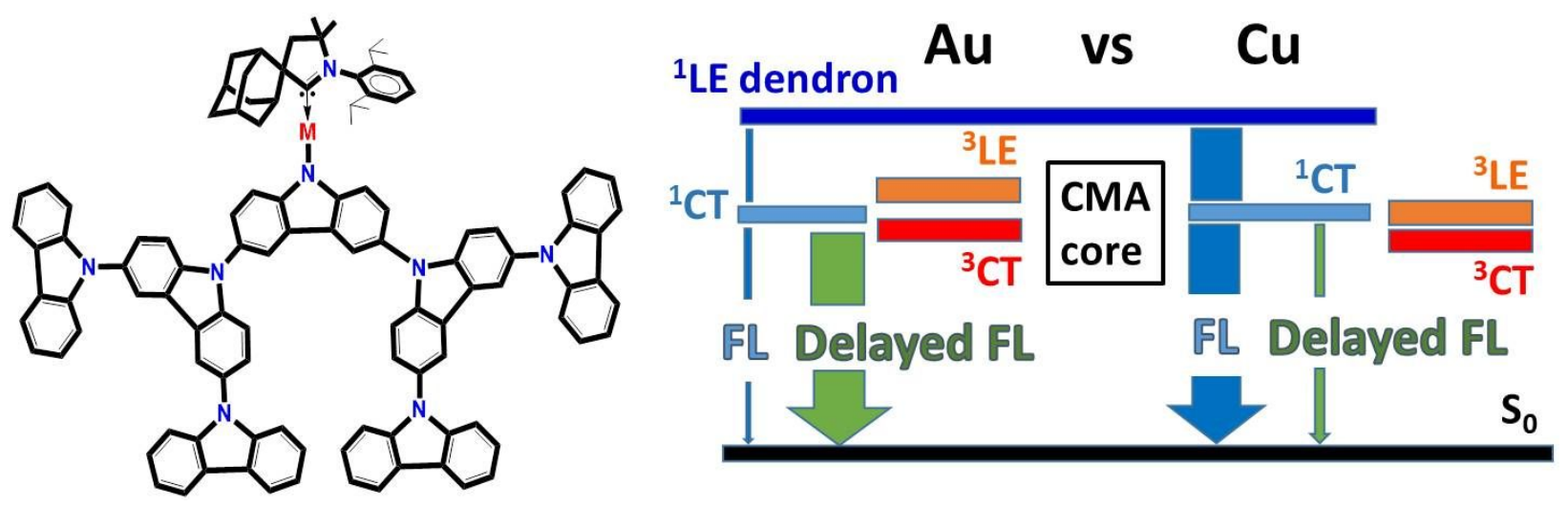

\begin{abstract}
:
Light-emitting carbene-metal amide (CMA) complexes bearing first and second generation carbazole dendron ligands are reported, $\left({ }^{\mathrm{Ad}} \mathrm{L}\right) \mathrm{M}\left(\mathrm{G}_{\mathrm{n}}\right),\left(\mathrm{M}=\mathrm{Cu}\right.$ and $\mathrm{Au} ; \mathrm{G}_{n}$ carbazole dendrimer generation, where $n=1$ and 2 ; ${ }^{A d} \mathrm{~L}=$ adamantyl-substituted cyclic (alkyl)amino)carbene). The thermal stability of the complexes increases with each dendrimer generation. Cyclic voltammetry indicates that the HOMO/LUMO energy levels are largely unaffected by the size of the dendron, while first reduction and oxidation processes show a quasi-reversible character. The gold complexes in toluene at room temperature show photoluminescent quantum yields (PLQYs) of up to $51.5 \%$ for the first and $78 \%$ for the second generation. Varied temperature transient
\end{abstract}


photoluminescence decay is consistent with a thermally activated process indicating a delayed fluorescence-type emission mechanism. Neat films show excited state lifetimes composed of prompt and dominant sub-microsecond delayed components, with radiative constants of up to $10^{6} \mathrm{~s}^{-1}$. Solution-processed organic light-emitting diodes (OLEDs) for first generation copper (1) and gold (2) dendrimers $\left({ }^{A d} L\right) M\left(G_{1}\right)$ have been fabricated with external quantum efficiencies (EQEs) of 5.5\% for copper and $10.3 \%$ for gold at practical brightness.

\section{- INTRODUCTION}

Since the discovery of electroluminescent conjugated poly(phenylene vinylene) by Friend and co-workers, ${ }^{1,2}$ polymer-based organic light emitting diodes (PLEDs) have attracted much academic and industrial interest. Light-emitting polymers can be deposited as multilayer device stacks via an orthogonal solvent approach.,4 This discovery paved the way for solution processing as an alternative route to thermal vacuum deposition techniques which currently dominate the manufacture of solid state lighting and small/medium-sized OLED displays. Solution processing ${ }^{5,6}$ promises cost-efficient mass production of large-scale organic printed electronics products, for instance, electronic papers and large television displays. Recent industrial developments have improved the efficiencies of solution-processed PLEDs from an external quantum efficiency (EQE) of $0.1 \%$ and lifetimes of a few minutes to over $20 \% \mathrm{EQE}$ and an operating stability of tens of thousands of hours. ${ }^{7,8}$

Dendrimers are macromolecules constructed from a central core connected to several branching units (dendrons). ${ }^{9-12} \mathrm{~A}$ number of recent reports have described light-emitting compounds of dendritic structures which show either thermally activated delayed fluorescence $(\mathrm{TADF})^{13-18}$ or phosphorescence behavior, ${ }^{19-27}$ and which are suitable for solution processed OLEDs due to their high solubility and amorphous nature. The latter suppresses aggregation and crystallization in the solid state, which can lead to brittle failure of flexible devices upon bending. Moreover, dendrimers may offer advantages due to steric protection of the emissive core by the branching units, leading to reduced concentration quenching of the chromophore. ${ }^{28,29}$ It has also been shown that fully encapsulated dendrimers can be used in single-component OLEDs, such that a single molecule fulfils both host and guest functions, which is an important step towards the simplification of OLED structure. ${ }^{30}$ 
We recently reported a number of highly emissive materials based on coinage metal complexes with carbene-metal-amide (CMA) structures; ${ }^{31-33}$ phosphorescent carbene-metalhalides and related emissive 2-, 3- and 4-coordinate complexes have also been described.34-35 This molecular design is based on complexes with linear geometry, where cyclic alkyl(amino) carbene (CAAC) donor ligands are linked by a coinage metal to acceptors such as carbazolate, resulting in rotationally flexible donor-metal-acceptor type structures. We have demonstrated that such a molecular design enables solution- and vapor-processed OLEDs with near-100\% internal quantum efficiencies at high brightness. ${ }^{36-38}$ Here, we report the synthesis and characterization of carbene-metal-amide emitters based on carbazole dendrons, together with their performance in solution-processed OLED devices.

\section{- RESULTS AND DISCUSSION}

Synthesis and structure. The reaction of copper and gold chloride complexes of adamantyl-substituted cyclic (alkyl)(amino) carbenes ${ }^{39-41}$ with first $\left(\mathrm{G}_{1}\right)$ and second generation $\left(\mathrm{G}_{2}\right)$ carbazolate dendrimers in the presence of the $\mathrm{NaO}{ }^{t} \mathrm{Bu}$ gave the complexes $\left({ }^{\mathrm{Ad}} \mathrm{L}\right) \mathrm{M}\left(\mathrm{G}_{\mathrm{n}}\right)(\mathbf{1}-\mathbf{4})$ in high yields (Scheme 1). The carbazole dendrons themselves were obtained by optimized Ullmann coupling. ${ }^{42-44}$ In all cases an adamantyl-substituted CAAC ligand was chosen $\left({ }^{\operatorname{Ad}} \mathrm{L}\right)$, which had previously been shown to give optimal photoemission. ${ }^{36,37}$ The complexes are white or slightly yellow solids and are stable for long periods of time in air and in solution in nonprotic organic solvents (with the exception of $\mathrm{CH}_{2} \mathrm{Cl}_{2}$ ). Complexes $\mathbf{1}-\mathbf{4}$ possess good solubility in aromatic solvents (toluene, chlorobenzene, 1,2-difluorobenzene), THF, dichloromethane, or DMF but are only poorly soluble in hexane, acetonitrile and ethanol. 
4
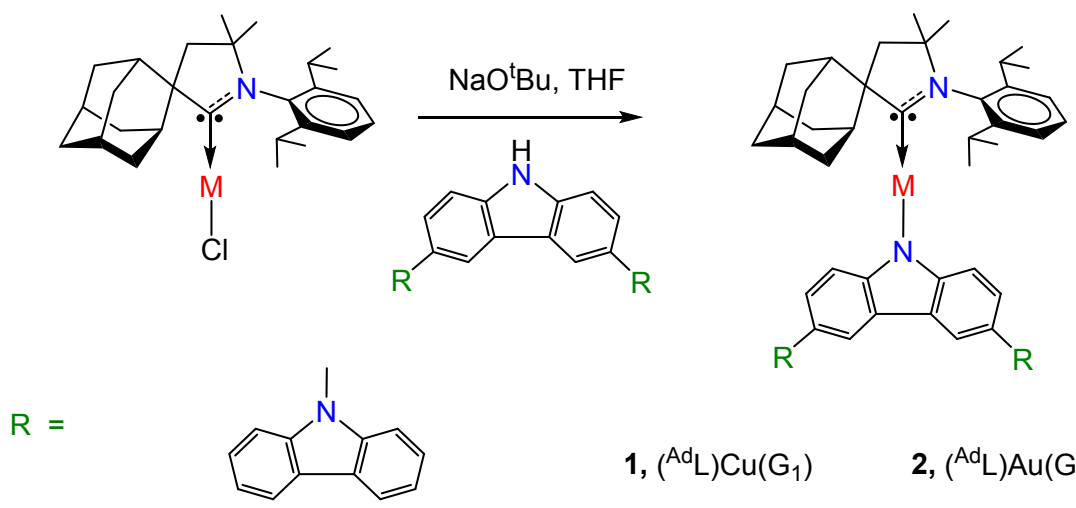

1, $\left({ }^{\mathrm{Ad}} \mathrm{L}\right) \mathrm{Cu}\left(\mathrm{G}_{1}\right) \quad$ 2, $\left({ }^{\mathrm{Ad}} \mathrm{L}\right) \mathrm{Au}\left(\mathrm{G}_{1}\right)$

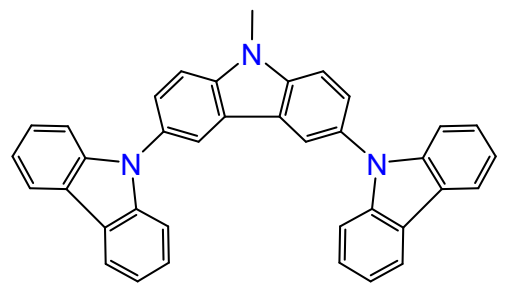

3, $\left({ }^{\mathrm{Ad}} \mathrm{L}\right) \mathrm{Cu}\left(\mathrm{G}_{2}\right)$

4, $\left({ }^{\mathrm{Ad}} \mathrm{L}\right) \mathrm{Au}\left(\mathrm{G}_{2}\right)$

Scheme 1. Preparation of carbene metal carbazole dendrimers $\left({ }^{A d} L\right) M\left(G_{n}\right)(\mathbf{1}-\mathbf{4})$.

Crystals of 2 were obtained by slow diffusion of hexane into a dichloromethane solution. All attempts to crystallize the second generation materials were unsuccessful. Complex 2 crystallizes with one molecule of $\mathrm{CH}_{2} \mathrm{Cl}_{2}$ (Figure 1). The crystal structure confirmed that 2 is monomeric, with the typical two-coordinate linear geometry of gold(I). The C1-Au1 and N2Aul bond lengths are negligibly different from the structure of the zeroth generation complex $\left({ }^{\mathrm{Ad}} \mathrm{L}\right) \mathrm{Au}$ (carbazolate) $(\mathbf{2}, \mathrm{R}=\mathrm{H}) .{ }^{36}$ The dihedral angle between $\mathrm{C} 2-\mathrm{C} 1-\mathrm{N} 1$ (CAAC) and C28-N2C39 (carbazole) of $12.2^{\circ}$ is $6.5^{\circ}$ smaller than in ( $\left.{ }^{\mathrm{Ad}} \mathrm{L}\right) \mathrm{Au}($ carbazolate). This smaller torsion angle for 2 is likely due to weak intermolecular $\mathrm{C}-\mathrm{H} \cdots \mathrm{Cl}$ interactions between complex 2 and the $\mathrm{CH}_{2} \mathrm{Cl}_{2}$ solvate molecules. The carbazole units are oriented almost perpendicular to one another (Figure 1). 


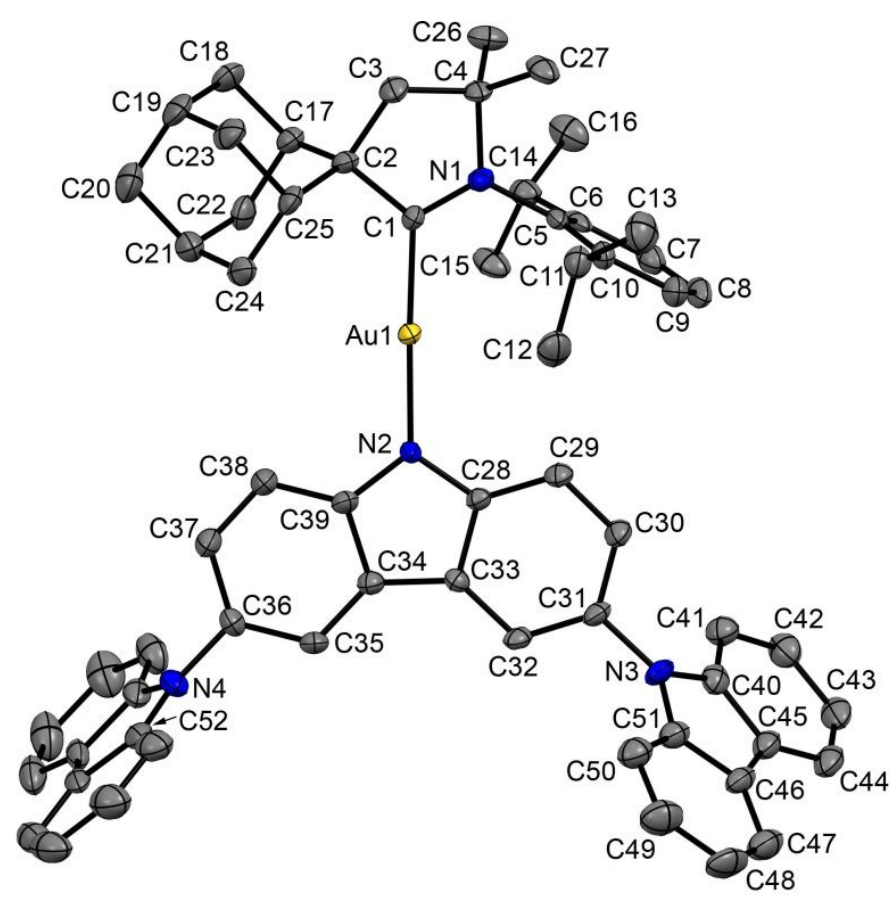

Figure 1. Crystal structures of the complex $\left({ }^{\mathrm{Ad}} \mathrm{L}\right) \mathrm{AuG}_{1} \cdot \mathrm{CH}_{2} \mathrm{Cl}_{2}\left(\mathbf{2} \cdot \mathrm{CH}_{2} \mathrm{Cl}_{2}\right)$. Ellipsoids are shown at $50 \%$ probability. Hydrogen atoms and the $\mathrm{CH}_{2} \mathrm{Cl}_{2}$ solvate molecule are omitted for clarity. Selected bond lengths $[\AA]$ and angles $\left[^{\circ}\right]$ : $\mathrm{Au}-\mathrm{C} 1$ 1.993(6), Au-N2 2.025(4), C1-C2 1.523(8), C1-N1 1.295(7), N2-C28 1.383(7), N2-C39 1.383(7), C1-Au-N2 177.6(2); torsion angles C52N4-C36-C35 85.7(8) and C51-N3-C31-C32 64.0(8); dihedral angle between best planes C2$\mathrm{C} 1-\mathrm{N} 1(\mathrm{CAAC})$ and C28-N2-C39 (carbazole) $=12.2^{\circ}$.

Thermal and electrochemical properties. The thermal behavior of 1-4 as solid powders was investigated by thermal gravimetric analysis (TGA) and differential scanning calorimetry (DSC). The $\mathrm{G}_{1}$ compounds 1 and 2 decompose above $340{ }^{\circ} \mathrm{C}$, while the second generation complexes 3 and 4 decompose above $360^{\circ} \mathrm{C}$. The decomposition occurs in two steps. The first step can be associated with the elimination of the carbene ligand, according to the weight loss of ca. $40 \%$ for the $\mathrm{G}_{1}$ and $c a .25 \%$ for the $\mathrm{G}_{2}$ compounds, which correlates with the weight of ${ }^{\mathrm{Ad}} \mathrm{L}$ (Figure S1). The second decomposition process is likely associated with the decomposition of the remaining oligocarbazole ligand.

Freshly prepared samples of 1-4 are amorphous. Compounds $\mathbf{1}$ and $\mathbf{2}$ show significant exothermic transition at 256 and $246{ }^{\circ} \mathrm{C}$ which can be associated with the crystallization temperature $\left(T_{c}\right)$ of the amorphous fraction (Figure $\mathrm{S} 1$ ). $T_{c}$ was not observed for the $\mathrm{G}_{2}$ materials, due to high molecular masses of $\mathbf{3}$ and $\mathbf{4}$. This follows the usual trend when crystallization is completely suppressed for higher generation of dendrimers ${ }^{45,46}$ and can be explained by the 
restrained molecular movement induced by the bulky carbazole dendrons. Therefore, the absence of crystallinity in $\mathrm{G}_{2}$ system is beneficial for forming and maintaining emissive films in an amorphous state for the development of flexible OLEDs.

The redox behavior of the 1-4 was analyzed in THF solution using $\left[{ }^{n} \mathrm{Bu}_{4} \mathrm{~N}\right] \mathrm{PF}_{6}$ as the supporting electrolyte. Examples of cyclic voltammograms for first and second generation dendrimers are shown in Figure S2, while the electrochemical data are collected in Table 1. The $\mathrm{G}_{1}$ and $\mathrm{G}_{2}$ complexes show a quasi-reversible one-electron reduction process. ${ }^{32,36}$ Its potential is largely unaffected by the generation of the dendrimer. The quasi-reversible character of the reduction process is more pronounced in higher generation dendrimers and for gold complexes compared to copper analogues (Table 1). ${ }^{47}$ The copper and gold $\mathrm{G}_{2}$ compounds $\mathbf{3}$ and $\mathbf{4}$ possess a second quasi-reversible reduction (see, Figure S2) with a potential close to the THF discharge. The potential of the second reduction is independent of the nature of the metal, which allowed us to tentatively assign it to reduction centered on the carbazole dendron.

Table 1. Formal electrode potentials (peak position $E_{\mathrm{p}}$ for irreversible and $E_{1 / 2}$ for quasireversible processes $(*), V$, vs. $\left.\mathrm{FeCp}_{2}\right)$, onset potentials $\left(E, V, v s . \mathrm{FeCp}_{2}\right)$, peak-to-peak separation in parentheses for quasi-reversible processes $\left(\triangle E_{p}\right.$ in $\left.\mathrm{mV}\right), E_{H O M O} / E_{L U M O}(e \mathrm{~V})$ and band gap values $(\Delta E, e \mathrm{~V})$ for the redox changes exhibited by copper and gold complexes. ${ }^{a}$

\begin{tabular}{|c|c|c|c|c|c|c|c|c|c|}
\hline \multirow{2}{*}{ Complex } & \multicolumn{3}{|c|}{ Reduction } & \multirow{2}{*}{$\begin{array}{l}E_{L U M O} \\
\mathrm{eV}\end{array}$} & \multicolumn{3}{|c|}{ Oxidation } & \multirow{2}{*}{$\begin{array}{l}E_{\text {Номо }} \\
\mathrm{eV}\end{array}$} & \multirow{2}{*}{$\begin{array}{l}\Delta E \\
\mathrm{eV}\end{array}$} \\
\hline & $E_{2 \mathrm{nd}}$ & $E_{1 \mathrm{st}}$ & $E_{\text {onset red }}$ & & $E_{1 \mathrm{st}}$ & $E_{\text {onset ox }}$ & $E_{2 \mathrm{nd}}$ & & \\
\hline$\left({ }^{\mathrm{Ad}} \mathrm{L}\right) \mathrm{CuG}_{1}(\mathbf{1})$ & - & $\begin{array}{c}-2.89 * \\
(140)\end{array}$ & -2.80 & -2.59 & $\begin{array}{c}+0.34 * \\
(116)\end{array}$ & +0.19 & +0.57 & -5.58 & 2.98 \\
\hline$\left({ }^{\mathrm{Ad}} \mathrm{L}\right) \mathrm{AuG}_{1}(\mathbf{2})$ & - & $\begin{array}{r}-2.76^{*} \\
(148)\end{array}$ & -2.67 & -2.72 & $\begin{array}{c}+0.34 * \\
(85)\end{array}$ & +0.22 & +0.76 & -5.61 & 2.89 \\
\hline$\left({ }^{\mathrm{Ad}} \mathrm{L}\right) \mathrm{CuG}_{2}(\mathbf{3})$ & $\begin{array}{c}-3.11^{*} \\
(190)\end{array}$ & $\begin{array}{c}-2.86^{*} \\
(136)\end{array}$ & -2.77 & -2.62 & +0.35 & +0.28 & - & -5.67 & 3.05 \\
\hline$\left({ }^{\mathrm{Ad}} \mathrm{L}\right) \mathrm{AuG}_{2}(\mathbf{4})$ & $\begin{array}{c}-3.11^{*} \\
(180)\end{array}$ & $\begin{array}{c}-2.79^{*} \\
(130)\end{array}$ & -2.71 & -2.68 & $\begin{array}{c}+0.39 * \\
(140)\end{array}$ & +0.29 & - & -5.68 & 3.00 \\
\hline
\end{tabular}


${ }^{a}$ Measured in THF solution, recorded using a glassy carbon electrode, concentration $1.4 \mathrm{~m} M$, supporting electrolyte $\left[{ }^{n} \mathrm{Bu}_{4} \mathrm{~N}\right]\left[\mathrm{PF}_{6}\right](0.13 M)$, measured at $0.1 \mathrm{~V} \mathrm{~s}^{-1} ; E_{\text {HOMO }}=-\left(E_{\text {onset ox } F c / F c^{+}}+\right.$ 5.39) $\mathrm{eV} ; E_{L U M O}=-\left(E_{\text {onset red } F C / F_{C^{+}}}+5.39\right) e \mathrm{~V}_{.}^{[56]}$

Unlike the zeroth generation compounds $\left({ }^{\mathrm{Ad}} \mathrm{L}\right) \mathrm{M}($ carbazolate $)(\mathrm{M}=\mathrm{Cu}$ and $\mathrm{Au}),{ }^{36}$ the first oxidation process shows a quasi-reversible character, with a well-defined back-peak observable in 1, 2 and 4 (see, Figure S2). An irreversible or quasi-reversible character of the oxidation processes has previously been reported for aniline and carbazole compounds and was attributed to an electropolymerization or cross-linking process. ${ }^{4-51}$ The oxidation processes is largely centered on the core carbazole unit for all compounds $\mathbf{1 - 4}$, on the basis of similar oxidation potential observed for $\mathrm{G}_{0}$ analogues $\left({ }^{\mathrm{Ad}} \mathrm{L}\right) \mathrm{M}$ (carbazolate). The onset of the first oxidation potential shifts by $c a .+100 \mathrm{mV}$ from the first to second generation dendrimers. A similar trend was reported for dendritic $\operatorname{Ir}(\mathrm{III})$ and $\mathrm{Au}(\mathrm{III})$ carbazole complexes. ${ }^{52-55}$ It was explained by a small negative inductive effect imposed by the nitrogen atom, leading to a slightly lower lying HOMO. ${ }^{19,43}$ HOMO/LUMO energy levels were determined from the onset potentials for oxidation and reduction processes of 1-4 (Table 1) ${ }^{56}$ which are in good agreement with previously reported values for carbazole dendrimers identified by photoelectron spectroscopy. ${ }^{57}$ Poly(9-vinylcarbazole) (PVK) was identified as a good host for 1-4. The quasi-reversible character of the first oxidation and reduction processes suggests that 1-4 may potentially be more robust emitters under electrical excitation compared to their parent compounds $\left({ }^{\mathrm{Ad}} \mathrm{L}\right) \mathrm{M}($ carbazolate $)(\mathrm{M}=\mathrm{Cu}$ and $\mathrm{Au})$.

\section{Photophysical properties.}

The UV/vis absorption spectra of 1-4 were collected in various media (Figures 2 and S3; Table 2 and SI, Table S1). In solution, the short wavelength region of the spectra show intense well-structured absorptions due to the $\pi-\pi^{*}$ intraligand (IL) transitions of the oligocarbazole and the CAAC ligands. The absorption at $309 \mathrm{~nm}$ is primarily due to the core carbazole $\pi-\pi^{*}$ transition (Figure S3), with molar extinction coefficients increasing with each dendrimer generation. All carbazole dendrons show relatively strong $\pi-\pi^{*}$ absorptions at longer overlap with a broad ligand-to-ligand charge transfer L(M)LCT $\left\{\pi(\right.$ carbazole $\left.)-\pi^{*}(\mathrm{CAAC})\right\}$ band from 
ca. 360 to $440 \mathrm{~nm}$. The extinction coefficients of the CT absorptions increase with each dendrimer generation, indicating a higher oscillator strength for the direct transitions from core carbazole (HOMO) to CAAC carbene (LUMO). This observation is in contrast with the behavior of purely organic carbazole dendrimers ${ }^{57}$ but in line with dendritic $\operatorname{Ir}(\mathrm{III}),{ }^{52} \mathrm{Pt}(\mathrm{II}),{ }^{53}$ and $\mathrm{Au}(\mathrm{III})$ complexes. ${ }^{54}$ The absorption CT band for 1 and 2 blue-shifts by $c a .20 \mathrm{~nm}$ with increasing solvent polarity (from toluene to $o$-dichlorobenzene, Figure S3). For bulkier second generation compounds 3 and 4 the position of the CT band is less affected by solvent polarity. The UV/Vis absorption spectra were also recorded for 1-4 neat and 20\%-doped films in PVK (Figure 2, S3). The neat film absorption profiles are similar to toluene solutions, superimposed upon a broad tail whose origin is likely to be scattering by the solid film. In in PVK host-guest films this tail largely obscures the CT band. (Figures 2 and S3).

(a)

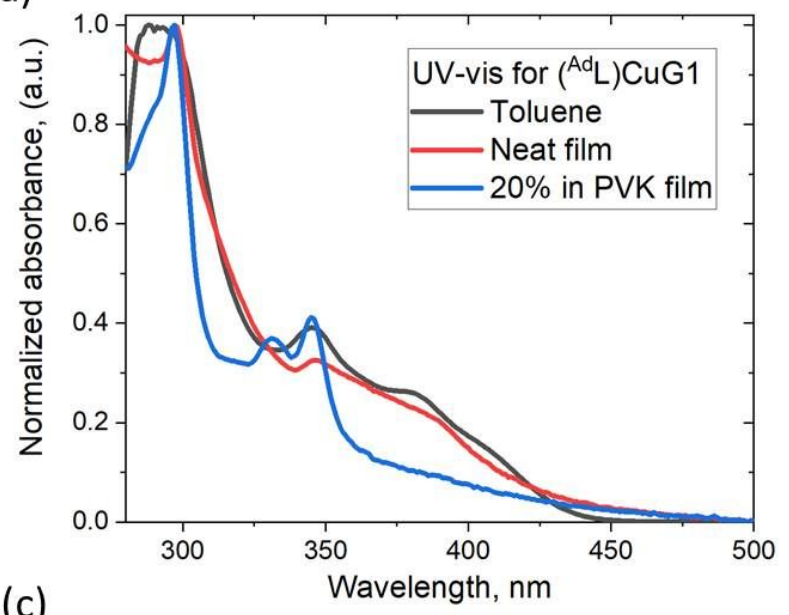

(c)

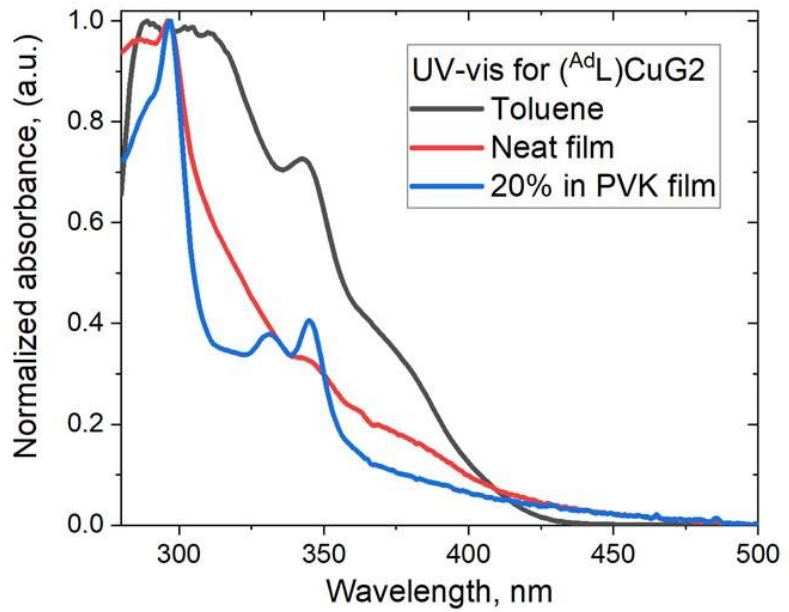

(b)
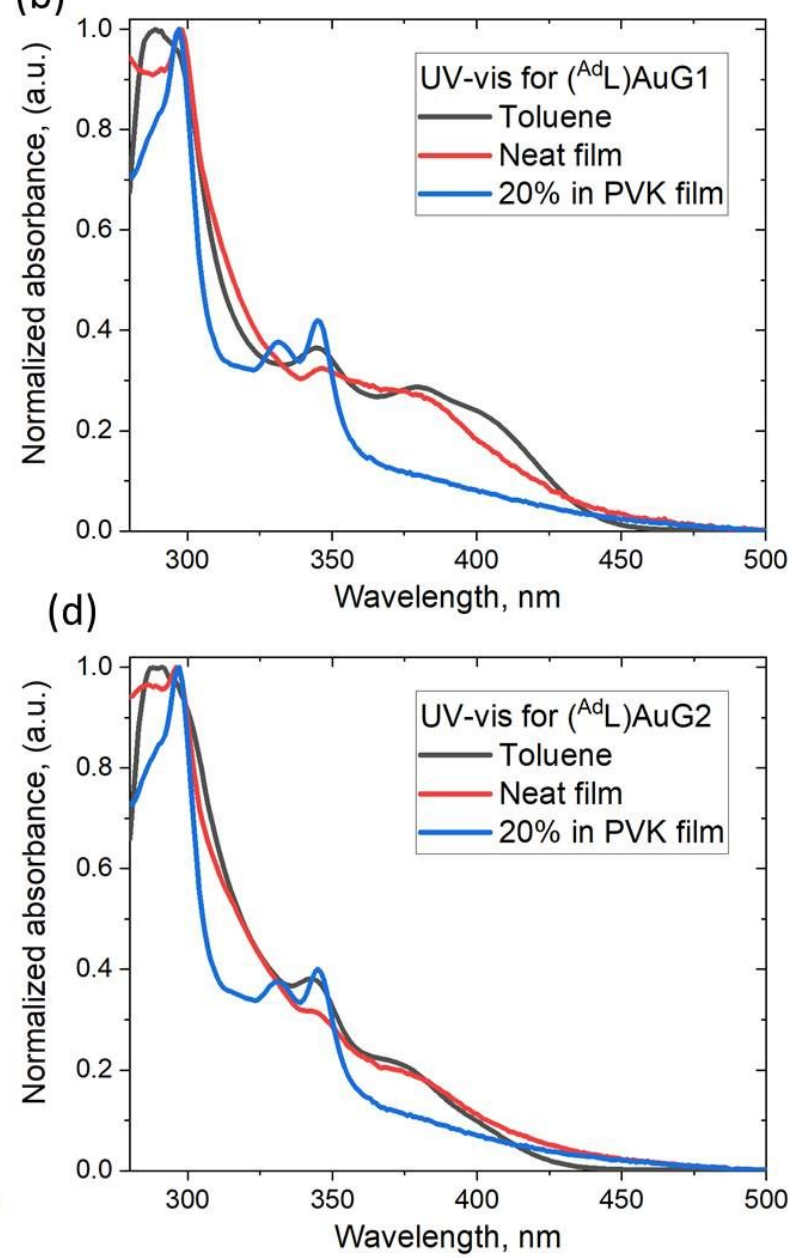
Figure 2. UV-vis spectra in toluene solution and films (neat and 20\% in PVK) for copper 1 (a) and 3 (c), gold 2 (b) and 4 (d) complexes.

To elucidate the effect of the carbazole dendrimer generations on emission properties, we measured the photoluminescence of $\mathbf{1 - 4}$ under various conditions (Table 2 and SI, Table S1). All complexes are green emitters in the solid state and in solution, showing featureless emission profiles if excited at the CT absorption band of the $\left({ }^{\mathrm{Ad}} \mathrm{L}\right) \mathrm{M}$ (carbazolate) core unit (Figures 2, 3, and S3). Compared to the gold compounds 2 and $\mathbf{4}$ the PL bands of the copper complexes 1 and 3 are blue-shifted by ca. $10 \mathrm{~nm}$ in all media. All dendrimers show the most blue-shifted PL in amorphous powder form (Figures 2 and S3) compared to the PL of processed neat (20 nm) and $20 \mathrm{wt} \%$ PVK films $(10 \mathrm{~nm})$. This contrasts with a much larger red-shift, of up to $60 \mathrm{~nm}$, observed between powder and processed film PL spectra for the zeroth generation complexes $\left({ }^{\mathrm{Ad}} \mathrm{L}\right) \mathrm{M}$ (carbazolate) $(\mathrm{M}=\mathrm{Cu}, \mathrm{CMA} 2 ; \mathrm{M}=\mathrm{Au}, \mathrm{CMA} 1)$ (Figures 3 and S4). ${ }^{36}$ This implies that interactions between chromophores and their environment are suppressed as the dendron generation is increased, with the large carbazole dendrimer capable of isolating the CT core from intermolecular interactions in both films and solutions.

In solution, 1-4 show weak solvatochromism, with PL red-shifting by 5-10 nm with increasing solvent polarity (toluene to $o$-dichlorobenzene), unlike the shift of $>100 \mathrm{~nm}$ experienced by many organic TADF emitters. ${ }^{58}$ The second generation dendrimers 3 and $\mathbf{4}$ show emission peaks blue-shifted by ca. $20 \mathrm{~nm}$ for solutions and films compared to very similar PL profiles of first 1/2 and zeroeth CMA1/2 dendrimer generations (Figures 3 and S3). Similar results were observed previously and explained by the slightly increasing electron-withdrawing nature of the dendron ligands. ${ }^{43,53,54}$ This phenomenon is in line with shallower HOMOs for the G2 compounds 3 and $\mathbf{4}$ observed by electrochemistry (Table 1). 

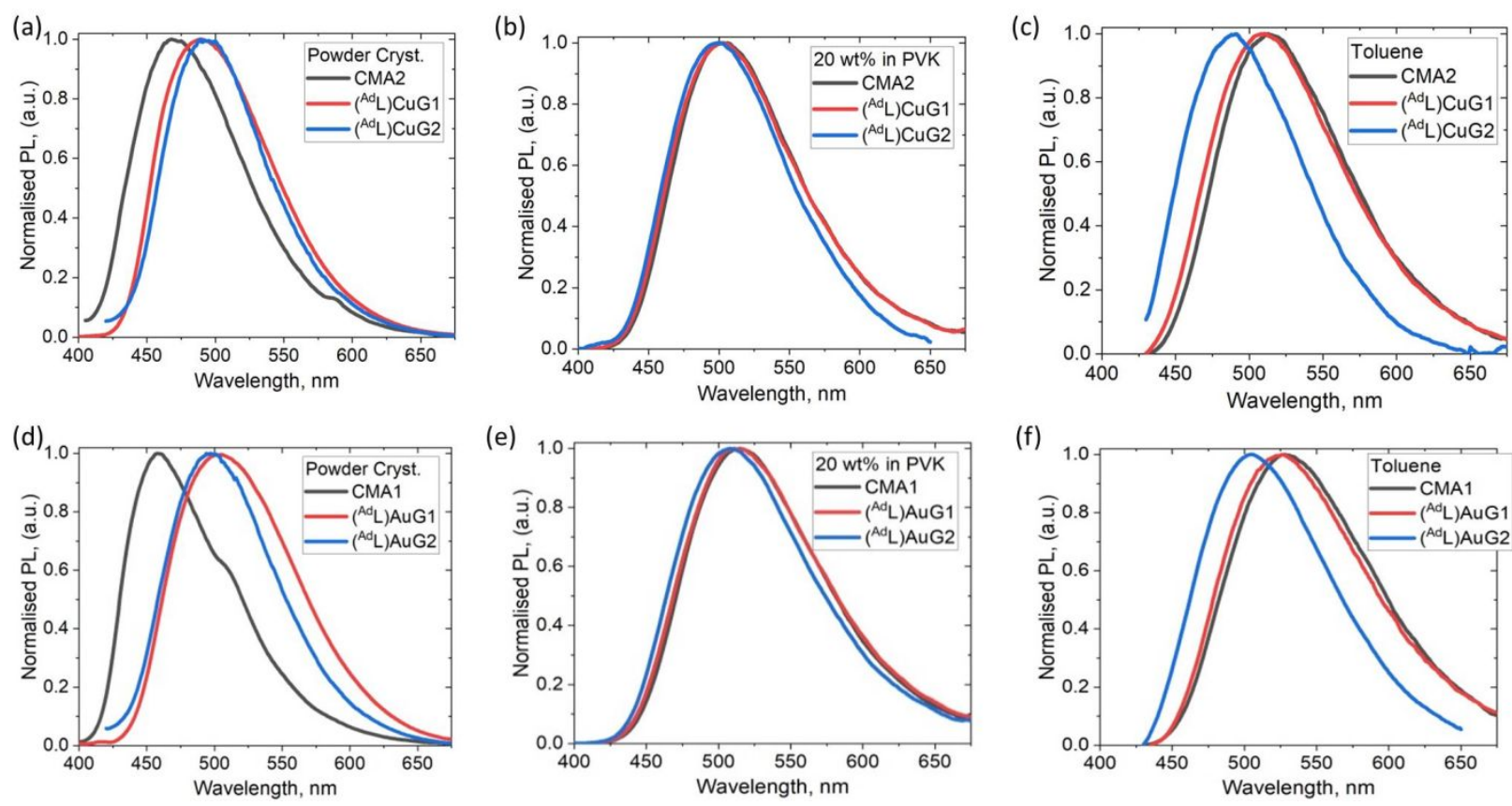

Figure 3. Emission spectra in the crystalline powder state; as $20 \mathrm{wt} \%$-doped film in PVK; in toluene solution (excitation at $390 \mathrm{~nm}$ ) for copper complexes CMA2, $\left({ }^{\mathrm{Ad}} \mathrm{L}\right) \mathrm{CuG} 1$ and $\left({ }^{\mathrm{Ad}} \mathrm{L}\right) \mathrm{CuG} 2$ (a-c, top); and gold complexes CMA1, $\left({ }^{\mathrm{Ad}} \mathrm{L}\right) \mathrm{AuG1}$ and $\left({ }^{\mathrm{Ad}} \mathrm{L}\right) \mathrm{AuG} 2$ (d-f, bottom).

The PL quantum yields (PLQYs) of 1-4 were measured in films and in solutions to identify the best candidates for OLED fabrication. The PLQY values for the spin-cast films are in the range of 12 to $40.5 \%$ (Table S1). The gold compounds 2 and 4 display the highest PLQY values both in $20 \mathrm{wt} \%$-doped PVK films and in toluene solutions (Table 2). All PLQY values are much reduced if measured in air, indicating the involvement of triplet states in photoluminescence.

We measured PL spectra with varied excitation wavelengths $(280-400 \mathrm{~nm})$ in search of possible higher lying excited states which could be involved in the emission process. Usually light-emitting dendrimers do not show locally excited emissions from the branched part of the molecule, which is an indication of the efficient energy transfer from the dendron to the core of the compounds. ${ }^{59,60}$ Excitation of $\mathbf{1}$ and $\mathbf{3}$ at $340 \mathrm{~nm}\left(\pi-\pi^{*}\right.$ transition of the carbazole dendron, see theoretical considerations) leads to significant emission at $393 \mathrm{~nm}$ together with CT-emission from the dendrimer's core (Figure 4 and S5). This carbazole fluorescence is not sensitive to oxygen (Figure S5). Compared to the copper compounds $\mathbf{1}$ and $\mathbf{3}$, the gold analogues $\mathbf{2}$ and $\mathbf{4}$ excited in the range of 300-440 nm show higher intensity CT emissions (Figures 4 and S5), 
indicative of better energy transfer from the carbazole donor to the carbene-metal acceptor unit in the case of gold compared to copper.
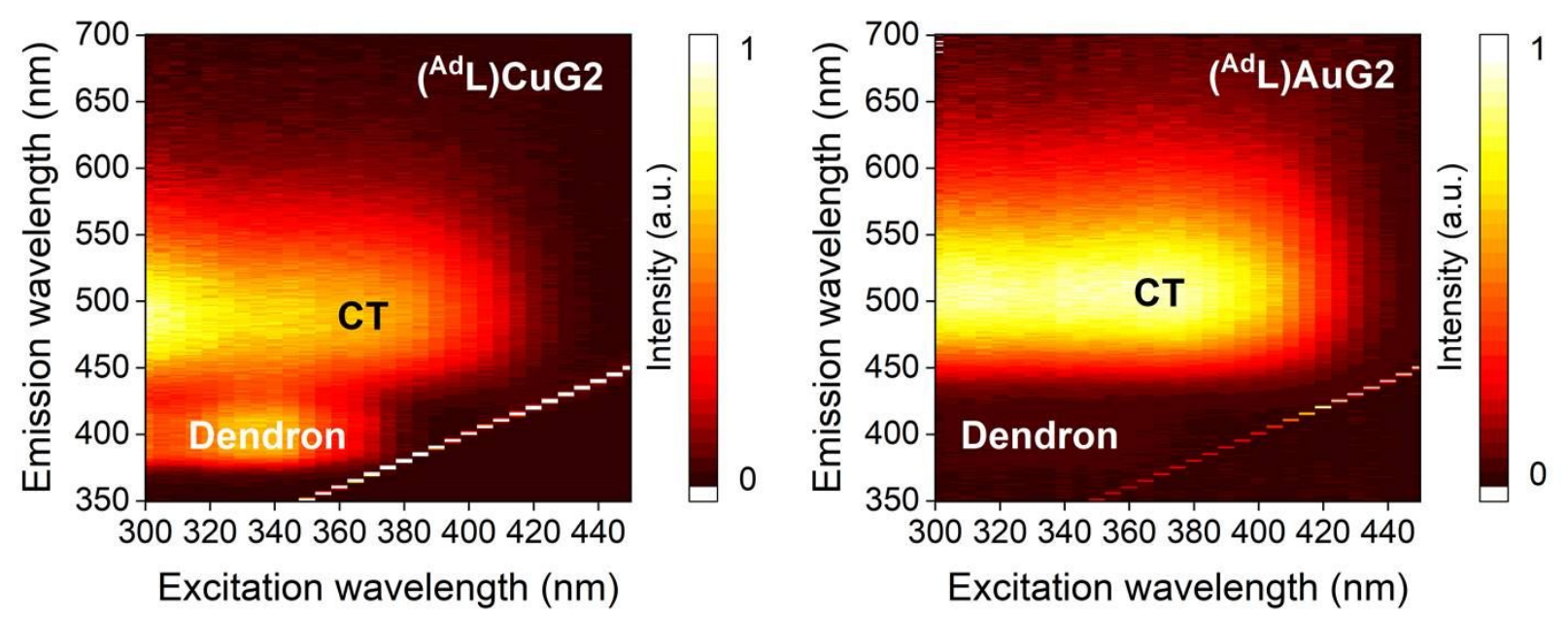

Figure 4. Emission-excitation maps for 3 (left) and 4 (right) in toluene solution.
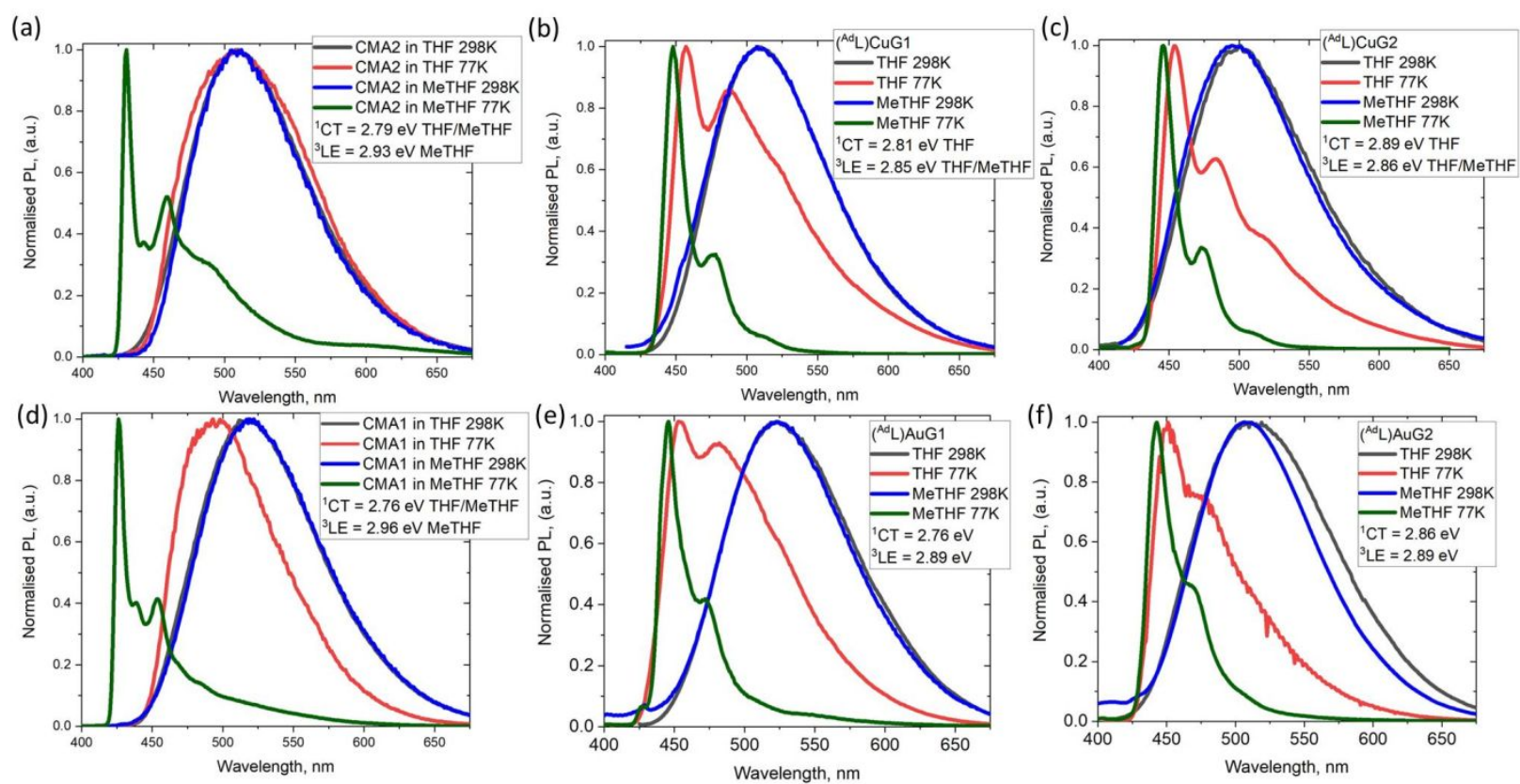

Figure 5. Emission spectra for CMA2, $\left({ }^{\mathrm{Ad}} \mathrm{L}\right) \mathrm{CuG1}(\mathbf{1})$ and $\left({ }^{\mathrm{Ad}} \mathrm{L}\right) \mathrm{CuG} 2(3)$ (top) and for CMA1, $\left({ }^{\mathrm{Ad}} \mathrm{L}\right) \mathrm{AuG} 1(\mathbf{2})$ and $\left({ }^{\mathrm{Ad}} \mathrm{L}\right) \mathrm{AuG} 2(\mathbf{4})$ (bottom) in THF and in MeTHF solutions at 77 and $298 \mathrm{~K}$ (excitation at $390 \mathrm{~nm}$, under nitrogen). 
The charge transfer singlet state $\left({ }^{l} C T\right)$ and local excited triplet state $\left({ }^{3} L E\right)$ energies were estimated from the onset values of the blue emission edge of the PL spectra at $295 \mathrm{~K}$ and $77 \mathrm{~K}$, respectively (Figure 5). The upper estimate of the ${ }^{3} L E$ triplet state energy is $2.86 \mathrm{eV}$ for copper $\mathbf{1 / 3}$ and $2.89 \mathrm{eV}$ for gold $\mathbf{2} / \mathbf{4}$ (Table 2, Figure 5). The lower estimate of the singlet state energy has been measured from the emission spectra in THF solutions of $\mathbf{1 - 4}$, where lower-energy conformations can be accessed. This analysis leads to the calculated values for the $\triangle E\left({ }^{1} C T-{ }^{3} L E\right)$ energy gap which are negative for $\mathbf{1}, \mathbf{2}$ and $\mathbf{4}$ and positive for copper complex $\mathbf{3}$ (Table 2). Zeroth generation complexes CMA1 and CMA2 show the largest negative $\triangle E\left({ }^{1} C T-{ }^{3} L E\right)$ of -0.2 and $0.14 \mathrm{eV}$ in MeTHF while in THF solutions the CT emission remains dominant at 77K (Figure 5). Based on PLQY values in PVK films and their radiative rates, we identify compounds 1, 2 and 4 as the most promising candidates for OLED fabrication. We do not observe a correlation between $\triangle E\left({ }^{l} C T-{ }^{3} L E\right)$ and radiative decay rate.

Table 2. Emission data of 1-4 in toluene and in PVK host. The data for the $\mathrm{G}_{0}$ compounds $\left({ }^{\mathrm{Ad}} \mathrm{L}\right) \mathrm{AuCz}(\mathbf{C M A 1})$ and $\left({ }^{\mathrm{Ad}} \mathrm{L}\right) \mathrm{CuCz}(\mathbf{C M A 2}){ }^{36}$ are included for comparison.

\begin{tabular}{|c|c|c|c|c|c|c|c|c|c|}
\hline & \multicolumn{3}{|c|}{ CMA1 } & \multicolumn{3}{|c|}{ CMA2 } & \multicolumn{3}{|c|}{1} \\
\hline & toluene & THF & $\begin{array}{l}\mathrm{PVK}^{a} \\
\text { matrix }\end{array}$ & toluene & THF & $\begin{array}{l}\mathrm{PVK}^{a} \\
\text { matrix }\end{array}$ & toluene & THF & $\begin{array}{l}\mathrm{PVK}^{a} \\
\text { matrix }\end{array}$ \\
\hline$\lambda_{\mathrm{em}}(\mathrm{nm})$ & 528 & 531 & 512 & 513 & 516 & 502 & 511 & 514 & 502 \\
\hline$\tau(\mu s)$ & 1.25 & 1.29 & 0.92 & 2.1 & 3.0 & 2.89 & 0.79 & 1.58 & 3.0 \\
\hline $\begin{array}{c}\Phi(\%, 300 \mathrm{~K} \\
\left.\mathrm{N}_{2} / \text { Air }\right)\end{array}$ & 98 & 80 & $86 / 37$ & 71 & 40 & $69.4 / 31$ & 27.7 & 43.1 & $33 / 23$ \\
\hline$k_{\mathrm{r}}\left(10^{5} \mathrm{~s}^{-1}\right)$ & 7.8 & 6.1 & 9.3 & 3.3 & 1.3 & 2.4 & 3.5 & 2.7 & 1.1 \\
\hline$k_{\mathrm{nr}}\left(10^{5} \mathrm{~s}^{-1}\right)$ & 0.16 & 1.5 & 1.5 & 1.3 & 1.9 & 1.0 & 9.1 & 3.6 & 2.2 \\
\hline${ }^{I} \mathrm{CT} /{ }^{\beta} \mathrm{LE}(\mathrm{eV})^{b}$ & & $2.76 / 2.96$ & & & $2.79 / 2.93$ & & & $2.81 / 2.85$ & \\
\hline \multirow[t]{3}{*}{$\Delta E\left({ }^{l} C T-{ }^{3} L E\right)^{b}$} & & $-0.20 \mathrm{eV}$ & & & $-0.14 \mathrm{eV}$ & & & $-0.04 \mathrm{eV}$ & \\
\hline & & 2 & & & 3 & & & 4 & \\
\hline & toluene & THF & $\begin{array}{l}\mathrm{PVK}^{a} \\
\text { matrix }\end{array}$ & toluene & THF & $\begin{array}{l}\mathrm{PVK}^{a} \\
\text { matrix }\end{array}$ & toluene & THF & $\begin{array}{l}\mathrm{PVK}^{a} \\
\text { matrix }\end{array}$ \\
\hline$\lambda_{\mathrm{em}}(\mathrm{nm})$ & 526 & 524 & 510 & 491 & 506 & 498 & 505 & 513 & 508 \\
\hline
\end{tabular}




\begin{tabular}{cccccccccc}
$\tau(\mu \mathrm{s})$ & 0.67 & 0.54 & 0.66 & 0.83 & 2.77 & 1.97 & 0.79 & 0.88 & 1.06 \\
$\Phi(\%, 300 \mathrm{~K} ;$ & 51.5 & 51.3 & $68 / 49$ & 2.6 & 18 & $6 / 3$ & 78.2 & 67.8 & $47.5 / 26.5$ \\
$\mathrm{~N}_{2} /$ Air $)$ & & & & & & & & & \\
$k_{\mathrm{r}}\left(10^{5} \mathrm{~s}^{-1}\right)$ & 7.7 & 9.5 & 10.3 & 0.3 & 0.6 & 0.3 & 9.9 & 7.7 & 4.5 \\
$k_{\mathrm{nr}}\left(10^{5} \mathrm{~s}^{-1}\right)$ & 7.2 & 9.0 & 4.9 & 11.7 & 2.9 & 4.8 & 2.7 & 3.6 & 4.9 \\
${ }^{1} \mathrm{CT} /{ }^{3} \mathrm{LE}(\mathrm{eV})^{b}$ & & $2.76 / 2.89$ & & & $2.89 / 2.86$ & & & $2.86 / 2.89$ \\
$\Delta E\left({ }^{1} \mathrm{CT}-{ }^{3} \mathrm{LE}\right)^{b}$ & & $-0.13 \mathrm{eV}$ & & $0.03 \mathrm{eV}$ & & & $-0.03 \mathrm{eV}$ \\
\hline
\end{tabular}

${ }^{a}$ PVK films were spun from $20 \mathrm{mg} / \mathrm{mL}$ chlorobenzene solutions for 45 seconds at $2000 \mathrm{rpm}$ on a quartz substrate; ${ }^{b} \mathrm{CT}$ and ${ }^{3} \mathrm{LE}$ energy levels for $\mathbf{1 - 4}$ based on the onset values of the emission spectra blue edge at $77 \mathrm{~K}$ in THF and MeTHF glasses and in solution at $298 \mathrm{~K}$.

\section{Transient PL and kinetic parameters.}

Solutions of $\mathbf{1}-\mathbf{4}$ show mono-exponential kinetics in time-resolved photoluminescence decays (Figure 6b, Table 2 and SI Table S1). By contrast, time-resolved photoluminescence decays of neat films and of $20 \mathrm{wt} \%$-doped PVK films are non-exponential, indicating a range of excited state lifetimes. Such behavior is consistent with chromophores adopting a range of conformations and short-range interactions in solution-processed films. Characteristic decay lifetimes (1- $e^{-1}$ centile) (Figure 6a) for the copper complexes $\mathbf{1}$ and $\mathbf{3}$ at ambient temperature are ca. 2-3 4 s, in contrast to $<1 \mu$ s for the gold analogues 2 and 4. In comparison with PLQE measurements on the same samples, the radiative rate constants for $\mathbf{1 / 3}$ are one order of magnitude smaller than $\mathbf{2} / \mathbf{4}$ in PVK films (Table 2). All transient PL decays were acquired over time scales of $20 \mu \mathrm{s}$ (solutions) and $100 \mu \mathrm{s}$ (neat and $20 \mathrm{wt} \%$-doped PVK films) to rule out the presence of long-lived phosphorescence components at room temperature (Figure 6a,b). 
(a)

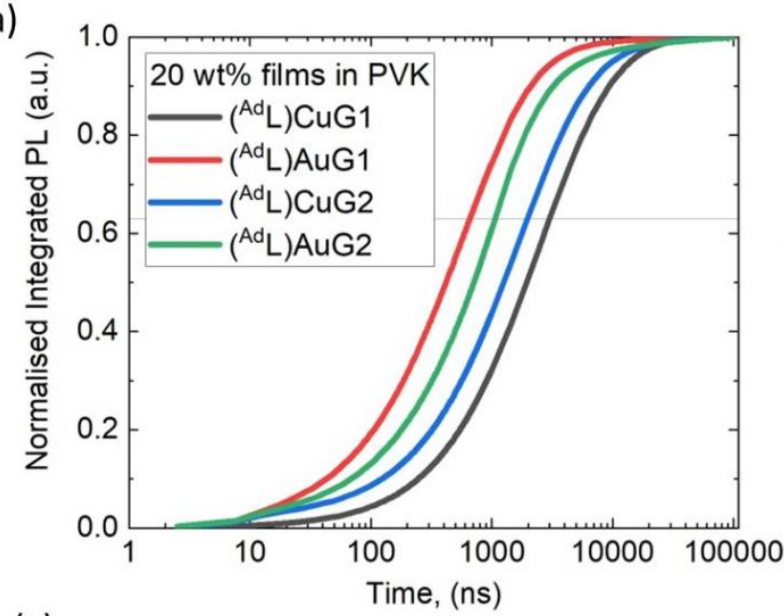

(c)

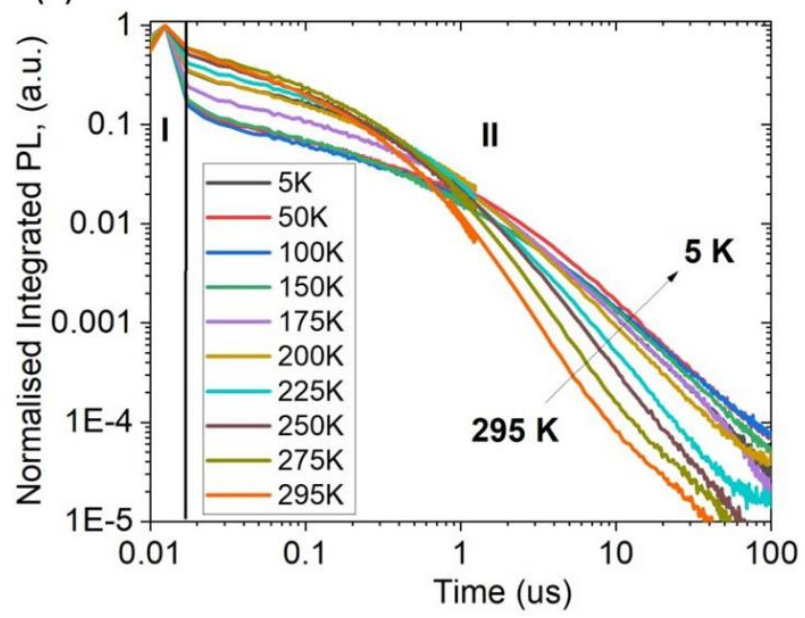

(b)

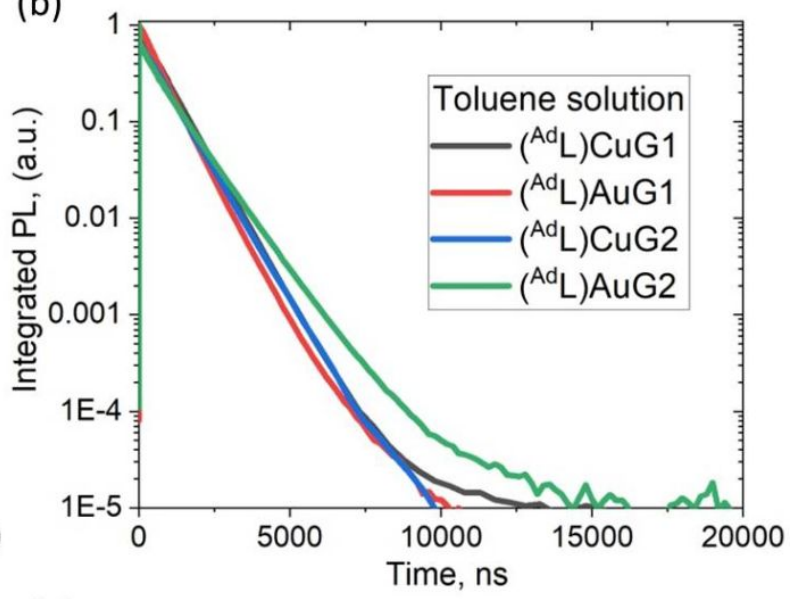

(d)

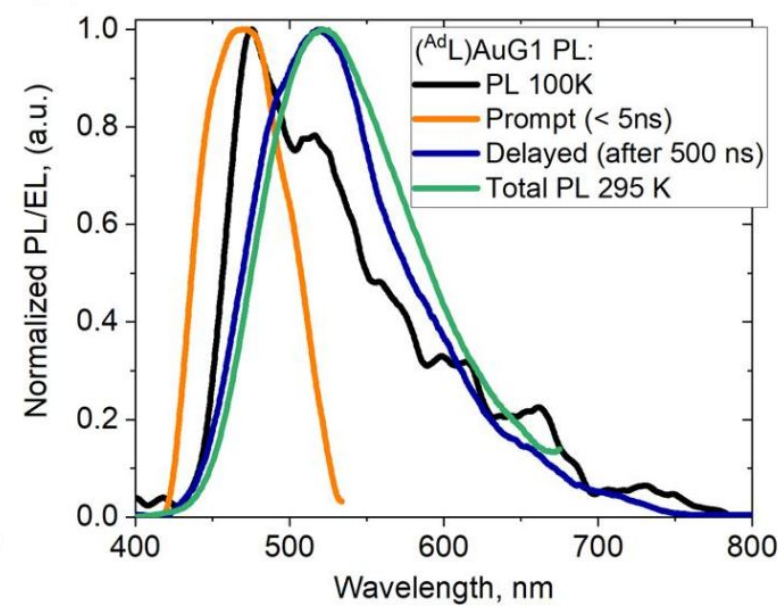

Figure 6. (a) Cumulative spectrally-integrated PL for 1-4 in $20 \mathrm{wt}-\%$ doped PVK films. Dashed line indicates $\left(1-e^{-1}\right)$ centile; (b) Time-resolved spectrally-integrated PL for $\mathbf{1 - 4}$ in toluene solution; (c) Temperature-dependent time-resolved PL for 2 as neat film. (d) Prompt (0-1 ns) and delayed (after $500 \mathrm{~ns}$ delay) emission spectra at $295 \mathrm{~K}$, phosphorescence (100 K), steady-state PL for 2 in spin-cast film.

Transient PL studies as a function of temperature were measured for $\mathbf{2}$ in a neat film (Figure 6). At all temperatures, PL transients are characterized by non-exponential kinetics over two distinct time regimes - nanosecond (I) and 100s of nanoseconds (II). Time regime (I) exhibits no significant $T$ dependence and is limited by the ICCD instrument response ( $3 \mathrm{~ns})$. We assign this to prompt fluorescence, with an estimated energy in excess of $2.95 \mathrm{eV}$. Spectral deconvolution indicates that its emission spectrum is blue-shifted compared to that at later times (Figure 6d). This small component is observed in various environments (neat films, PVK hostguest systems, and solutions, Figure S9). Luminescence in regime (II) is unstructured and 
thermally activated, with an activation energy of $92 \mathrm{meV}$ for 2 (Figure S6); lifetimes increase significantly on cooling, from $\tau_{\mathrm{II}}=280 \mathrm{~ns}$ at $300 \mathrm{~K}$ to $4.48 \mu$ s below $100 \mathrm{~K}$. This is consistent with a TADF-type emission process whereby delayed emission originates from a reservoir of triplet states, whose ability to relax to the singlet ground state is increased at elevated temperature. One of the features indicative of the TADF mechanism is the blue-shift of the emission maxima with increasing temperature. ${ }^{61-65} \mathrm{We}$ observe a red-shift of the delayed emission upon warming. We attribute this to emission from an ensemble of CT states in different local configurations within the solid film. The delayed regime accounts for $>90 \%$ of the total emission at room temperature (Figure S6). Note that the delayed fluorescence spectra after 500 ns and the neat film spectrum are essentially superimposable, see Figure 6d.

\section{Theoretical Considerations.}

We investigated the electronic structure of complexes 1-4 using density-functional theory (DFT) for the ground state and time-dependent DFT (TD-DFT) ${ }^{66}$ calculations for the excited states, using the MN15 functional by $\operatorname{Truhlar}^{67}$ in combination with def2-TZVP basis set by Ahlrichs. ${ }^{68-70}$ These molecules have a high dipole moment, of the order of 15-20 D in the ground state (see SI, Tables S2 and S3) oriented along the metal-nitrogen vector. This is reduced on excitation by charge transfer from the carbazole to the carbene ligand (G2 molecules) and changes direction for G0 and G1 complexes.

The calculated $\mathrm{S}_{0}$ geometry is in a good agreement with the crystal structure of $\mathbf{2}$ and adopts co-planar conformation (CAAC carbene and metal-bound carbazole ligands are lying nearly in the same plane). The optimized geometry for $\mathrm{S}_{1}$ and $\mathrm{T}_{1}$ states show that the $\mathrm{C}-\mathrm{N}$ (CAAC) bond is elongated by 0.07-0.09 $\AA$, with simultaneous shortening of C1-Metal and elongation of N1-Metal bonds. The distortion from linear geometry calculated for copper complexes (Figure 7, C1-M-N2 angle $\alpha=11$ and $17^{\circ}$ for $\mathbf{1}$ and $\mathbf{3}$, respectively) is significantly larger than for gold (with $\alpha$ up to $9^{\circ}$ ). Calculations suggest that the optimized $\mathrm{S}_{1}$ geometry for G2 complexes is ca. $20^{\circ}$ less twisted than for G1 compounds and is systematically lower for copper complexes (see SI, Figure S7). This compares with inter-ligand twist angles in the $\mathrm{S}_{1}$ states of $66^{\circ}$ for zeroth generation copper CMA2 and nearly $90^{\circ}$ for gold CMA1 analogues. The relaxed $\mathrm{S}_{1}$ energy is weakly dependent on the twist angle, while $\mathrm{T}_{1}$ has a stronger angular dependency (see SI, Figure $\mathrm{S} 7$ ). The calculated exchange energy $\Delta E\left(\mathrm{~S}_{1}-\mathrm{T}_{1}\right)$ depends on the twist angle and 
increases from $0.11 \mathrm{eV}$ for the first generation to $0.15 \mathrm{eV}$ for the second generation dendrimers (Figure S7). Gold dendrimer 2 shows the smallest deviations from linear geometry in the excited state and has the largest twist angle $\left(39^{\circ}\right)$, which suggests 2 as the most promising OLED material candidate where $S_{1}$ and $T_{1}$ states could verge on degeneracy. ${ }^{71,72}$.

The calculations show that the ligand-to-ligand charge transfer (LLCT) from the carbazole dendron to the carbene defines both lowest energy states of the singlet and triplet manifold (Tables S2-S7). In 1-4 the HOMO is mostly delocalized over the carbazole dendron, with decreasing contribution of the metal atom from 5\% for zeroeth generation CMA1/CMA2 to $2.5 \%$ for $\mathbf{1} / \mathbf{2}$ and $c a .1 .5 \%$ for $\mathbf{3} / \mathbf{4}$, while the LUMOs are all very similar and centered on the $\mathrm{C}_{\text {carbene }} \mathrm{p}$-orbital. The calculated energy of the $\mathrm{S}_{0} \rightarrow \mathrm{S}_{1}$ absorption agrees well with first peak in UV-vis spectrum in toluene ca. $400 \mathrm{~nm}$ for $\mathbf{1} / \mathbf{2}$ (ca. $3.05 \mathrm{eV}$ ) and $c a .390$ for $\mathbf{3} / \mathbf{4}$ (ca. $3.18 \mathrm{eV}$ ). The vertical $\mathrm{S}_{0} \rightarrow \mathrm{S}_{1}$ transitions are composed of mixed charge transfer HOMO/HOMO-2 $\rightarrow$ LUMO (for $\mathbf{1 / 2}$ ) and HOMO/HOMO-4 $\rightarrow$ LUMO transitions (for $\mathbf{3} / \mathbf{4}$ ). The contribution of the pure HOMO $\rightarrow$ LUMO transition decreases from $98 \%$ for CMA1/CMA2 to $90 \%$ for $\mathbf{1} / \mathbf{2}$ and $70 \%$ for $\mathbf{3} / \mathbf{4}$ (SI, Tables S4 and S5). The calculated geometries for $S_{1}$ and $T_{1}$ states show a decrease by $10-15^{\circ}$ for the angle between core and branched carbazole planes compared with the ground state $\mathrm{S}_{0}\left(20-40^{\circ}\right.$ decrease compared with crystal structure of 2$)$ This indicates that core and branched carbazole units may adopt conformations allowing conjugation in the excited state which may lead to competition between localized and CT emissions. The calculated absorptions for copper 1/3 (3.66 eV; $\left.\mathrm{S}_{0} \rightarrow \mathrm{S}_{3}\right)$ and gold $\mathbf{2} / \mathbf{4}\left(3.70 \mathrm{eV} ; \mathrm{S}_{0} \rightarrow \mathrm{S}_{2}\right)$ are in good agreement with the experimental absorption at $343 \mathrm{~nm}(3.61 \mathrm{eV})$ which is present in all dendrimer generations and corresponds to the carbazole dendron. Indeed, vertical excitations $\mathrm{S}_{0} \rightarrow \mathrm{S}_{3}$ (for copper) and $\mathrm{S}_{0} \rightarrow \mathrm{S}_{2}$ (for gold) lead to either locally excited core carbazole (Figure 7, HOMO $\rightarrow \mathrm{LUMO}+3$ for generation G1) or branched dendrimer units (HOMO $\rightarrow \mathrm{LUMO}+4$ for G2). Moreover the oscillator coefficients $(f)$ for these transitions are one third of the pure HOMO $\rightarrow$ LUMO transition and only increase with each dendrimer generation. This theoretical result explains the experimental observation of the emission from a higher lying excited state (3.46 eV, Figure 4), indicative of significant competing fluorescence emission from the dendron unit leading to reduced PLQY values, particularly for copper $\mathbf{1 / 3}$ (Table 2). 


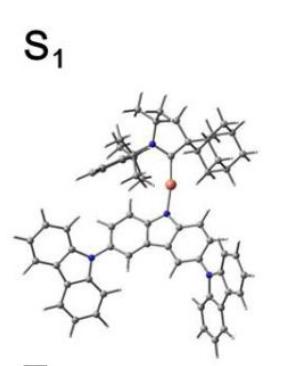

$\mathrm{T}_{1}$
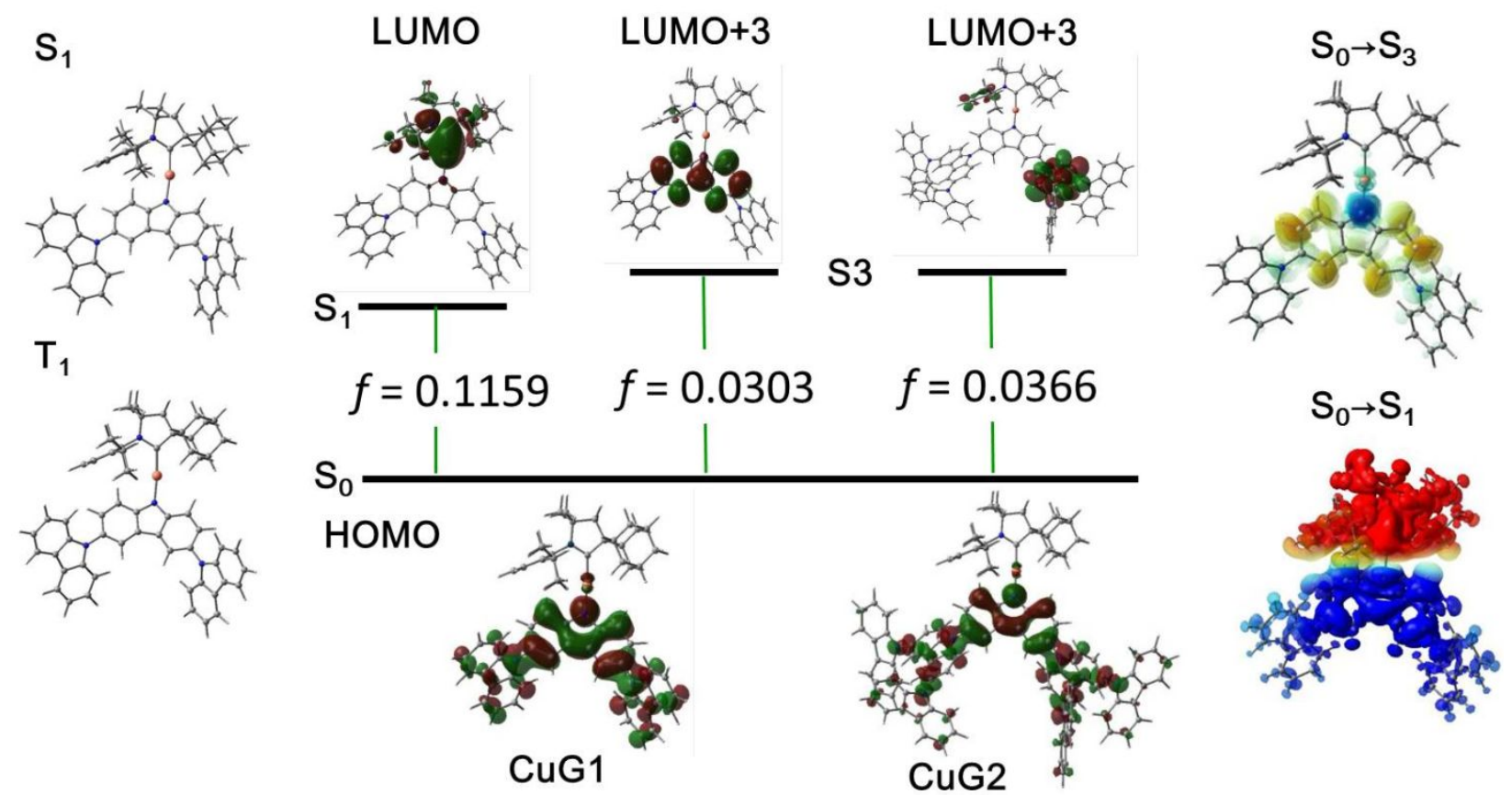

Figure 7. Left: Optimized geometries for copper complex 1 in the first excited $S_{1}$ and $T_{1}$ states. Middle: molecular-orbital distribution of the HOMO, LUMO, and LUMO+3 for 1 and 3 involved in vertical excitations $\left(\mathrm{S}_{0} \rightarrow \mathrm{S}_{1} / \mathrm{S}_{3}\right)$. Right: Electrostatic potential maps of the charge transfer upon excitation $\left(\mathrm{S}_{0} \rightarrow \mathrm{S}_{1} / \mathrm{S}_{3}\right)$, where blue/ red indicate lower/higher electron density).

\section{Electroluminescent (EL) Properties.}

Solution-processed OLED devices were fabricated with copper 1 and gold compounds $2 / 4$ as emitters, with the architecture of ITO/ PEDOT:PSS (30 nm)/ poly[9,9-dioctylfluorene-co-N-(4butylphenyl)diphenylamine (TFB, $180 \mathrm{~nm}$ )/ PVK: 20\%wt emitter/ bathophenanthroline (Bphen, $70 \mathrm{~nm}) / \mathrm{LiF}(0.7 \mathrm{~nm}) / \mathrm{Al}(100 \mathrm{~nm})$. The choice of near-perfect orthogonal solvents (see SI) ensures the sequential deposition of organic layers, without affecting the thickness and interface structures of the underlying layers. ${ }^{73,74}$ In particular, a thick hole-transporting layer of TFB is important to ensure a balance of injected charges for exciton formation and recombination within the emissive layer and thus enhancing device performance. The devices produced peak EQEs of $5.6 \%, 10.6 \%$ and $3.7 \%$ for $\mathbf{1}, \mathbf{2}$, and 4 , respectively (Figure 8 , Table 3 ). In line with literature reports, second generation dendrimer 4 shows lower EQE compared with first generation 2 which is likely due to a lower carrier mobility in higher generation dendrimers. ${ }^{54}$ The EL spectra for the solution-processed OLEDs agree with the time-averaged PL and delayed fluorescence 
emission profiles (Figure 8). Devices made from 2, as discussed from its photophysical measurements, generated the best performance: they showed the lowest turn-on voltage $(3.2 \mathrm{~V})$, the least efficiency roll-off at higher current densities and practical luminance (EQE of $10.3 \%$ at $100 \mathrm{~cd} / \mathrm{m}^{2}$ and $10.0 \%$ at $1000 \mathrm{~cd} / \mathrm{m}^{2}$ ), peak EQE at $10.6 \%$, and high luminance (peaking at $29,000 \mathrm{~cd} / \mathrm{m}^{2}$ at $\left.\sim 15 \mathrm{~V}\right)$. The higher turn-on voltage and reduced EQE values for the second generation dendrimer 4 could be due an imbalance in charge injection and lower mobility. Further device optimization to tune the layer thicknesses and doping concentration may be necessary, due to the larger dendrons in the second generation 4 .

(a)

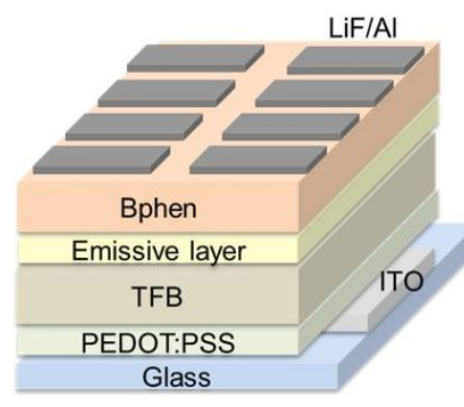

(b)

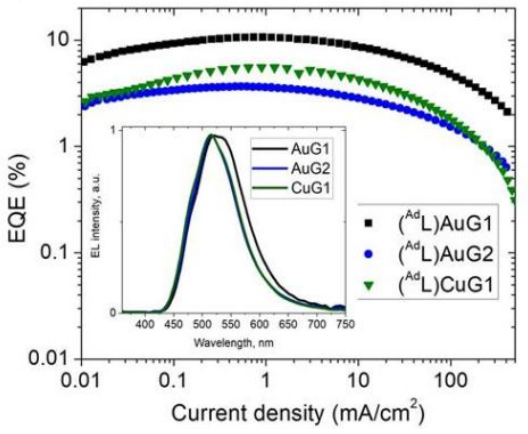

(c)

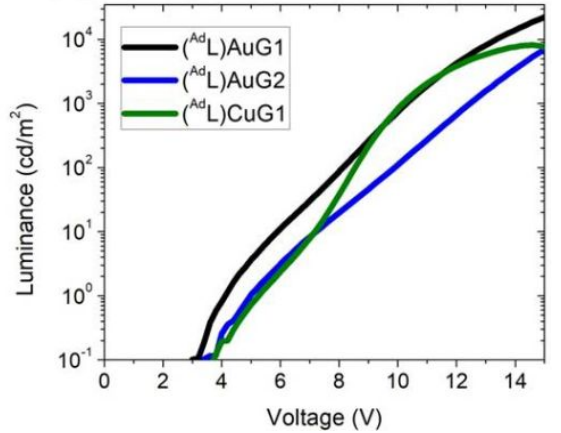

Figure 8. (a) Solution-processed OLED devices architectures based on $20 \mathrm{wt} \%$ doped PVK as the emissive layer (EML); (b) External quantum efficiencies vs. current density of champion OLEDs based on 1, 2, and $\mathbf{4}$ with inset showing their electroluminescence (EL) spectra; (c) Luminance-voltage characteristics for OLEDs based on 1, 2, and 4.

Table 3. Performance data of solution-processed OLEDs (20 wt- $\%$ doped in PVK).

\begin{tabular}{|c|c|c|c|c|c|c|}
\hline \multirow{2}{*}{ Dopant } & \multirow{2}{*}{$\begin{array}{l}\mathrm{V}_{\mathrm{ON}} \\
{[\mathrm{V}]}\end{array}$} & \multirow{2}{*}{$\begin{array}{c}\text { Max. } \\
\text { Luminance } \\
{\left[\mathrm{cd} \mathrm{m}^{-2}\right]}\end{array}$} & \multicolumn{3}{|c|}{$\eta_{\mathrm{EQE}, \mathrm{EL}}[\%]$} & \multirow{2}{*}{$\begin{array}{l}\mathrm{CIE}^{a} \\
(\mathrm{x}, \mathrm{y})\end{array}$} \\
\hline & & & Max. & $100 \mathrm{~cd} \mathrm{~m}^{-2}$ & $1000 \mathrm{~cd} \mathrm{~m}^{-2}$ & \\
\hline 1 & 3.8 & 8100 & 5.6 & 5.5 & 4.6 & $(0.37,0.60)$ \\
\hline 2 & 3.2 & 29000 & 10.6 & 10.3 & 10.0 & $(0.39,0.58)$ \\
\hline 4 & 3.6 & 10000 & 3.7 & 3.6 & 2.8 & $(0.37,0.60)$ \\
\hline
\end{tabular}

${ }^{a}$ Commission Internationale de l'Éclairage (CIE) color coordinates

\section{- CONCLUSION}


In conclusion, emissive carbene-metal-amides (CMAs) with first- and second generation carbazole dendron ligands have been synthesized, with high quantum yields (up to $78 \%$ ) and short (sub-microsecond) excited state lifetimes. Their excellent thermal stability indicates that these dendrimers are suitable for the fabrication of OLED devices. The radiative rate constants of the gold compounds are one order of magnitude higher than those of the copper analogues. Complexes 1, 2 and 4 show dominant delayed fluorescence together with a small prompt fluorescence component. PL studies and TD-DFT calculations indicate the existence of higherlying excited states which affect the PL properties, particularly for $\mathbf{1}$ and $\mathbf{3}$. These dendritic complexes proved suitable for the fabrication of solution-processed OLEDs with EQEs of 10\% at the practical brightness of $1000 \mathrm{~cd} / \mathrm{m}^{2}$, and maximum luminance of $29,000 \mathrm{~cd} / \mathrm{m}^{2}$. The good solubility and amorphous properties of 1-4 suggest that they may be suitable for processing techniques such inkjet or roll-to-roll printing for the manufacture of flexible OLEDs.

\section{- ASSOCIATED CONTENT}

*S Supporting Information

The Supporting Information is available free of charge on the ACS Publications website at DOI: 10.1039/XXXXXX.

CCDC number 1568825 contains the supplementary crystallographic data for this paper. These data can be obtained free of charge from The Cambridge Crystallographic Data Centre via www.ccdc.cam.ac.uk/data request/cif. Detailed experimental procedures, single-crystal X-ray diffraction data, photophysical and OLED device characterization, and computational details.

\section{- AUTHOR INFORMATION}

Corresponding Authors

*E-mail: asromanov5@gmail.com

*E-mail: yang.lele@gmail.com

*E-mail: mikko.linnolahti@uef.fi

*E-mail: djnc3@cam.ac.uk

*E-mail:m.bochmann@uea.ac.uk

ORCID ID

Dr. A. S. Romanov: https://orcid.org/0000-0003-2617-6402 
Prof. Dr. M. Bochmann: https://orcid.org/0000-0001-7736-5428

Dr. D. Di https://orcid.org/0000-0003-0703-2809

Dr. L. Yang https://orcid.org/0000-0002-3697-171X

S. T. E. Jones https://orcid.org/0000-0001-6007-2530

Dr. D. Credgington https://orcid.org/0000-0003-4246-2118

Prof. Dr. M. Linnolahti https://orcid.org/0000-0003-0056-2698

Bluebell H. Drummond https://orcid.org/0000-0001-5940-8631

\section{Notes}

The authors declare no competing financial interest.

\section{- ACKNOWLEDGMENTS}

This work was supported by the European Research Council, the Royal Society and the Academy of Finland. M. B. is an ERC Advanced Investigator Award holder (grant no. 338944GOCAT). D.C. acknowledges support from the Royal Society (grant nos. UF130278 and RG140472). A.S.R. acknowledges support from the Royal Society (grant nos. URF $\backslash R 1 \backslash 180288$ and RGF\EA 181008$)$. L.Y. thanks the Agency of Science, Technology and Research (A*STAR, Singapore) for support. This work was supported by the EPSRC Cambridge NanoDTC, EP/L015978/1. The computations were made possible by use of the Finnish Grid and Cloud Infrastructure resources (urn:nbn:fi:research-infras-2016072533). We also thank the EPSRC UK National Mass Spectrometry Facility at Swansea University.

\section{- REFERENCES}

(1) Burroughes, J. H.; Bradley, D. D. C.; Brown, A. R.; Marks, R. N.; Mackay, K.; Friend, R. H.; Burn, P. L.; Holmes, A. B. Light-emitting diodes based on conjugated polymers. Nature 1990, $347,539-541$.

(2) Friend, R. H.; Gymer, R. W.; Holmes, A. B.; Burroughes, J. H.; Marks, R. N.; Taliani, C.; Bradley, D. D. C.; dos Santos, D. A.; Brédas, J. L.; Lögdlund, M.; Salaneck, W. R. Electroluminescence in conjugated polymers. Nature 1999, 397, 121-128.

(3) Meerholz, K. Enlightening solutions. Nature 2005, 437, 327-328. 
(4) Zakhidov, A. A.; Lee, J.-K.; Fong, H. H.; DeFranco, J. A.; Chatzichristidi, M.; Taylor, P. G.; Ober, C. K.; Malliaras, G. G. Hydrofluoroethers as Orthogonal Solvents for the Chemical Processing of Organic Electronic Materials. Adv. Mater. 2008, 20, 3481-3484.

(5) Burrows, P. E.; Forrest, S. R.; Thompson, M. E. Prospects and applications for organic lightemitting devices. Curr. Opin. Solid State Mater. Sci. 1997, 2, 236-243.

(6) Li, J.; Liu, D. Dendrimers for organic light-emitting diodes. J. Mater. Chem. 2009, 19, 75847591.

(7) Lee, B. R.; Jung, E. D.; Park, J. S.; Nam, Y. S.; Min, S. H.; Kim, B.-S.; Lee, K.-M.; Jeong, J.R.; Friend, R. H.; Kim, J.-S.; Kim S. O.; Song, M. H. Highly efficient inverted polymer lightemitting diodes using surface modifications of $\mathrm{ZnO}$ layer. Nat. Commun. 2014, 5, 4840.

(8) Sekine, C.; Tsubata, Y.; Yamada, T.; Kitano, M.; Doi, S. Recent progress of high performance polymer OLED and OPV materials for organic printed electronics. Sci. Technol. Adv. Mater. 2014, 15, 034203.

(9) Astruc, D. Electron-transfer processes in dendrimers and their implication in biology, catalysis, sensing and nanotechnology. Nat. Chem. 2012, 4, 255-267.

(10) Astruc, D.; Boisselier E.; Ornelas, C. Dendrimers Designed for Functions: From Physical, Photophysical, and Supramolecular Properties to Applications in Sensing, Catalysis, Molecular Electronics, Photonics, and Nanomedicine. Chem. Rev. 2010, 110, 1857-1959.

(11) Newkome, G. R.; Shreiner, C.; Dendrimers Derived from $1 \rightarrow 3$ Branching Motifs. Chem. Rev. 2010, 110, 6338-6442.

(12) Grayson, S. M.; Fréchet, J. M. J. Convergent Dendrons and Dendrimers: from Synthesis to Applications. Chem. Rev. 2001, 101, 3819-3868.

(13) Albrecht, K.; Matsuoka, K.; Yokoyama, D.; Sakai, Y.; Nakayama, A.; Fujita K.;

Yamamoto, K. Thermally activated delayed fluorescence OLEDs with fully solution processed organic layers exhibiting nearly 10\% external quantum efficiency. Chem. Commun. 2017, 53, 2439-2442.

(14) Wang, J.; Peng, J.; Yao, W.; Jiang, C.; Liu, C.; Zhang, C.; He, M.; Liu, R.; Xia, X.; Yao, C. Carbazole-dendrite-encapsulated electron acceptor core for constructing thermally activated delayed fluorescence emitters used in nondoped solution-processed organic light-emitting diodes. Org. Electron. 2017, 48, 262-270. 
(15) Matsuoka, K.; Albrecht, K.; Yamamoto K.; Fujita, K. Mulifunctional Dendritic Emitter: Aggregation-Induced Emission Enhanced, Thermally Activated Delayed Fluorescent Material for Solution-Processed Multilayered Organic Light-Emitting Diodes. Sci. Rep. 2017, 7:41780. (16) Kwon, T. W.; Alam M. M.; Jenekhe, S. A. n-Type Conjugated Dendrimers: Convergent Synthesis, Photophysics, Electroluminescence, and Use as Electron-Transport Materials for Light-Emitting Diodes. Chem. Mater. 2004, 16, 4657-4666.

(17) Qin, T.; Zhou, G.; Scheiber, H.; Bauer, R. E.; Baumgarten, M.; Anson, C. E.; List, E. J. W.; Müllen, K. Polytriphenylene dendrimers: a unique design for blue-light-emitting materials. Angew. Chem., Int. Ed. 2008, 47, 8292-8296.

(18) Hwang, S.; Moorefield, C. N.; Newkome, G. R. Dendritic macromolecules for organic lightemitting diodes. Chem. Soc. Rev. 2008, 37, 2543-2557.

(19) Lee, C. H.; Tang, M.-C.; Wong, Y.-C.; Chan, M.-Y.; Yam, V. W.-W. Sky-Blue-Emitting Dendritic Alkynylgold(III) Complexes for Solution-Processable Organic Light-Emitting Devices. J. Am. Chem. Soc. 2017, 139, 10539-10550 (and references therein). (20) Burn, P. L.; Lo S. C.; Samuel, I. D. W. The development of light-emitting dendrimers for displays. Adv. Mater. 2007, 19, 1675-1688.

(21) Zhou, G.; Wong, W.-Y.; Yang, X. New design tactics in OLEDs using functionalized 2phenylpyridine-type cyclometalates of iridium(III) and platinum(II). Chem.-Asian J. 2011, 6 , $1706-1727$.

(22) Lo, S.-C.; Male, N. A. H.; Markham, J. P. J.; Magennis, S.W.; Burn, P. L.; Salata, O. V.; Samuel, I. D. W. Green Phosphorescent Dendrimer for Light-Emitting Diodes. Adv. Mater. 2002, 14, 975.

(23) Lo, S.-C.; Harding, R. E.; Shipley, C. P.; Stevenson, S. G.; Burn, P. L.; Samuel, I. D. W. High-triplet-energy dendrons: enhancing the luminescence of deep blue phosphorescent iridium(III) complexes J. Am. Chem. Soc. 2009, 131, 16681-16688.

(24) Xia, D.; Wang, B.; Chen, B.; Wang, S.; Zhang, B.; Ding, J.; Wang, L.; Jing, X.; Wang, F. Self-host blue-emitting iridium dendrimer with carbazole dendrons: nondoped phosphorescent organic light-emitting diodes. Angew. Chem., Int. Ed. 2014, 53, 1048-1052.

(25) Zhou, G.; Wong, W.-Y.; Yao, B.; Xie, Z.; Wang, L. Triphenylamine-dendronized pure red iridium phosphors with superior OLED efficiency/color purity trade-offs. Angew. Chem., Int. Ed. 2007, 46, 1149-1151. 
(26) Zhu, M.; Zou, J.; He, X.; Yang, C.; Wu, H.; Zhong, C.; Qin J.; Cao, Y. Triphenylamine dendronized iridium(III) complexes: robust synthesis, highly efficient non-doped orange electrophosphorescence and the structure-property relationship. Chem. Mater. 2012, 24, 174 180.

(27) Qin, T.; Ding, J.; Wang, L.; Baumgarten, M.; Zhou, G.; Müllen, K. A divergent synthesis of very large polyphenylene dendrimers with iridium(III) cores: molecular size effect on the performance of phosphorescent organic light-emitting diodes. J. Am. Chem. Soc. 2009, 131, 14329-14336.

(28) Levell, J. W.; Lai, W.-Y.; Borthwick, R. J.; Burn, P. L.; Lo, S.-C.; Samuel, I. D. W. Carbazole/iridium dendrimer side-chain phosphorescent copolymers for efficient light emitting devices. New J. Chem. 2012, 36, 407-413.

(29) Li, Y.; Liu, Y.; Zhou, M. Synthesis and properties of a dendritic FRET donor-acceptor system with cationic iridium(III) complex core and carbazolyl periphery. Dalton Trans. 2012, $41,2582-2591$.

(30) Lo, S.-C.; Anthopoulos, T. D.; Namdas, E. B.; Burn, P. L.; Samuel, I. D. W. Encapsulated cores: host-free organic light-emitting diodes based on solution-processible electrophosphorescent dendrimers. Adv. Mater. 2005, 17, 1945-1948.

(31) Romanov, A. S.; Di, D.; Yang, L.; Fernandez-Cestau, J.; Becker, C. R.; James, C. E.; Zhu, B.; Linnolahti, M.; Credgington, D.; Bochmann, M. Highly photoluminescent copper carbene complexes based on prompt rather than delayed fluorescence. Chem. Commun. 2016, 52, 63796382 and Chem. Commun. 2018, 54, 3672.

(32) Romanov, A. S.; Becker, C. R.; James, C. E., Di, D., Credgington, D., Linnolahti, M.; Bochmann, M. Copper and gold cyclic (alkyl)(amino)carbene complexes with sub-microsecond photoemissions: structure and substituent effects on redox and luminescent properties. Chem. Eur. J. 2017, 23, 4625-4637.

(33) Romanov A. S.; Bochmann, M. Synthesis, structures and photoluminescence properties of silver complexes of cyclic (alkyl)(amino)carbenes. J. Organomet. Chem. 2017, 847, 114-120.

(34) Gernert, M.; Müller, U.; Haehnel, M.; Pflaum J.; Steffen, A. A cyclic alkyl(amino)carbene as two-atom $\pi$-chromophore leading to the first phosphorescent linear $\mathrm{Cu}^{\mathrm{I}}$ complexes. Chem. Eur. J. 2017, 23, 2206-2216. 
(35) Hamze, R.; Jazzar, R.; Soleilhavoup, M.; Djurovich, P. I., Bertrand, G.; Thompson, M. E. Phosphorescent 2-, 3- and 4-coordinate cyclic(alkyl)(amino)carbene (CAAC) Cu(I) complexes. Chem. Commun. 2017, 53, 9008-9011.

(36) Di, D.; Romanov, A. S.; Yang, L.; Richter, J. M.; Rivett, J. P. H.; Jones, S.; Thomas, T. H.; Jalebi, M. A.; Friend, R. H.; Linnolahti, M.; Bochmann, M.; Credgington, D. High-performance light-emitting diodes based on carbene-metal-amides. Science 2017, 356, 159-163.

(37) Conaghan, P. J.; Menke, S. M.; Romanov, A. S.; Jones, S. T. E.; Pearson, A. J.; Evans, E. W.; Bochmann, M.; Greenham, N. C.; Credgington, D. Efficient vacuum-processed lightemitting diodes based on carbene-metal-amides. Adv. Mater. 2018, 30, 1802285.

(38) Romanov, A. S.; Jones, S. T. E.; Yang, L.; Conaghan, P. J.; Di, D.; Linnolahti, M.; Credgington, D.; Bochmann, M. Mononuclear silver complexes for efficient solution and vacuum-processed OLEDs. Adv. Optical Mater. 2018, 6, 1801347.

(39) Lavallo, V.; Canac, Y.; Prasang, C.; Donnadieu, B.; Bertrand, G. Stable cyclic (alkyl)(amino)carbenes as rigid or flexible, bulky, electron-rich ligands for transition-metal catalysts: a quaternary carbon atom makes the difference. Angew. Chem. Int. Ed. 2005, 44, 5705-5709.

(40) Frey, G. D.; Dewhurst, R. D.; Kousar, S.; Donnadieu, B.; Bertrand, G. Cyclic (alkyl)(amino)carbene gold(I) complexes: a synthetic and structural investigation. J. Organomet. Chem. 2008, 693, 1674-1682.

(41) Romanov, A. S.; Bochmann, M. Gold(I) and gold(III) complexes of cyclic (alkyl)(amino)carbenes. Organometallics 2015, 34, 2439-2454.

(42) Klapars, A.; Antilla, J. C.; Huang, X.; Buchwald, S. L. A general and efficient copper catalyst for the amidation of aryl halides and the N-arylation of nitrogen heterocycles. J. Am. Chem. Soc. 2001, 123, 7727-7729.

(43) Albrecht, K.; Yamamoto K. Dendritic structure having a potential gradient: new synthesis and properties of carbazole dendrimers. J. Am. Chem. Soc. 2009, 131, 2244-2251. (44) Zhang, Y.; Zuniga, C.; Dengke, C.; Marder, S.; Kippelen, B. 2-Alkyl-5-phenyl oxadiazolecarbazole hosts for guests emitters. Patent application WO2012/088316 and PCT/US2011/066597. 
(45) Lo, S.-C.; Namdas, E. B.; Shipley, C. P.; Markham, J. P. J.; Anthopolous, T. D.; Burn, P. L.; Samuel, I. D. W. The synthesis and properties of iridium cored dendrimers with carbazole dendrons. Org. Electron. 2006, 7, 85-98.

(46) Zhao, L.; Wang, S.; Shao, S.; Ding, J.; Wang, L.; Jinga, X.; Wang, F. Stable and efficient deep-blue terfluorenes functionalized with carbazole dendrons for solution-processed organic light-emitting diodes. J. Mater. Chem. C 2015, 3, 8895-8903.

(47) For instance, the peak-to-peak separation $\Delta E_{p}$ is slightly smaller for the second generation $(4,130 \mathrm{mV})$ compared to the first generation $(2,148 \mathrm{mV})$ gold complexes. The $i_{\mathrm{pa}} / i_{\mathrm{pc}}$ ratio for the $\mathrm{G}_{1}$ gold complex 2 is much closer to unity even at low scan rates $\left(0.72\right.$ at $50 \mathrm{mVs}^{-1}$ and 0.80 at $\left.2.0 \mathrm{Vs}^{-1}\right)$ than that of the copper analogue $1\left(0.58\right.$ at $50 \mathrm{mVs}^{-1}$ and 0.75 at $\left.2.0 \mathrm{Vs}^{-1}\right)$.

(48) Karon, K.; Lapkowski, M. Carbazole electrochemistry: a short review. J. Solid State Electrochem. 2015, 19, 2601-2610.

(49) Sotzing, G. A.; Reddinger, J. L.; Katritzky, A. R.; Soloducho, J.; Musgrave, R.; Reynolds, J. R. Multiply colored electrochromic carbazole-based polymers. Chem. Mater. 1997, 9, 15781587.

(50) Yang, H.; Bard, A. J. The application of rapid scan cyclic voltammetry and digital simulation to the study of the mechanism of diphenylamine oxidation, radical cation dimerization, and polymerization in acetonitrile. J. Electroanal. Chem. 1991, 306, 87-109.

(51) Hsieh, B. R.; Litt, M. H. Poly(N-acylethylenimines) with pendant carbazole derivatives. 3. Electrochemical studies. Macromolecules 1986, 19, 521-529.

(52) Ding, J.; Gao, J.; Cheng, Y.; Xie, Z.; Wang, L.; Ma, D.; Jing, X.; Wang, F. Highly Efficient Green-Emitting Phosphorescent Iridium Dendrimers Based on Carbazole Dendrons. Adv. Funct. Mater. 2006, 16, 575-581.

(53) Kong, F. K.; Tang, M.-C.; Wong, Y.-C., Chan, M.-Y.; Yam, V. W.-W. Design Strategy for High-Performance Dendritic Carbazole-Containing Alkynylplatinum(II) Complexes and Their Application in Solution-Processable Organic Light-Emitting Devices. J. Am. Chem. Soc. 2016, $138,6281-6291$.

(54) Tang, M.-C.; Tsang, D. P.-K.; Chan, M. M.-Y.; Wong, K. M.-C.; Yam, V. W.-W. Dendritic Luminescent Gold(III) Complexes for Highly Efficient Solution-Processable Organic LightEmitting Devices. Angew. Chem. Int. Ed., 2013, 52, 446-449; 
(55) Knights, K. A.; Stevenson, S. G.; Shipley, C. P.; Lo, S.-C.; Olsen, S.; Harding, R.E.; Gambino, S.; Burn, P. L.; Samuel, I. D. W. A rapid route to carbazole containing dendrons and phosphorescent dendrimers. J. Mater. Chem. 2008, 18, 2121-2130.

(56) Cardona, C. M.; Li , W.; Kaifer, A. E.; Stockdale, D.; Bazan, G. C. Electrochemical considerations for determining absolute frontier orbital energy levels of conjugated polymers for solar cell applications. Adv. Mater. 2011, 23, 2367-2371.

(57) Albrecht, K.; Matsuoka, K.; Fujita, K.; Yamamoto, K. Carbazole dendrimers as solutionprocessable thermally activated delayed-fluorescence materials. Angew. Chem. Int. Ed. 2015, 54, $5677-5682$.

(58) Suzuki, K.; Kubo, S.; Shizu, K.; Fukushima, T.; Wakamiya, A.; Murata, Y.; Adachi, C.; Kaji, H. Angew.Chem. Int. Ed. 2015, 54, 15231-15235.

(59) Lo, S.-C.; Namdas, E. B.; Burn, P. L.; Samuel, I. D. F. Synthesis and Properties of Highly Efficient Electroluminescent Green Phosphorescent Iridium Cored Dendrimers. Macromolecules 2003, 36, 9721-9730.

(60) Palsson, L.-O.; Beavington, R.; Frampton, M. J.; Lupton, J. M.; Magennis, S. W.; Markham, J. P. J.; Pillow, J. N. G.; Burn, P. L.; Samuel, I. D. W. Synthesis and excited state spectroscopy of tris(distyrylbenzenyl)amine-cored electroluminescent dendrimers. Macromolecules 2002, 35 , 7891-7901.

(61) Leitl, M. J.; Zink, D. M.; Schinabeck, A.; Baumann, T.; Volz, D.; Yersin, H. Copper(I) complexes for thermally activated delayed fluorescence: from photophysical to device properties. Top. Curr. Chem. 2016, 374, 25.

(62) Yersin, H.; Rausch, A. F.; Czerwieniec, R.; Hofbeck, T.; Fischer, T. The triplet state of organo-transition metal compounds. Triplet harvesting and singlet harvesting for efficient OLEDs. Coord. Chem. Rev. 2011, 255, 2622-2652.

(63) Yersin, H.; Rausch, A. F.; Czerwieniec, R.; In: Brutting, W.; Adachi, C. (eds) Physics of organic semiconductors.. Wiley VCH: Weinheim, 2012, p 371.

(64) Parker, C. A.; Hatchard, C. G. Triplet-singlet emission in fluid solutions. Phosphorescence of eosin. Trans. Faraday Soc. 1961, 57, 1894-1904.

(65) Czerwieniec, R.; Yu. J.; Yersin, H. Blue-light emission of $\mathrm{Cu}(\mathrm{I})$ complexes and singlet harvesting. Inorg. Chem. 2011, 50, 8293-8301. 
(66) Furche, F.; Rappoport, D. Density functional methods for excited states: equilibrium structure and electronic spectra. In: Computational Photochemistry; M. Olivuccim, Ed.; Elsevier: Amsterdam, 2005, pp. 93-128.

(67) Yu, H.S.; He, X.; Li, S.L.; Truhlar, D.G. MN15: A Kohn-Sham global-hybrid exchangecorrelation density functional with broad accuracy for multi-reference and single-reference systems and noncovalent interactions. Chem. Sci. 2016, 7, 5032-5051.

(68) Weigend, F.; Häser, M.; Patzelt, H.; Ahlrichs, R. RI-MP2: optimized auxiliary basis sets and demonstration of efficiency. Chem. Phys. Lett. 1998, 294, 143-152.

(69) Weigend, F.; Ahlrichs, R. Balanced basis sets of split valence, triple zeta valence and quadruple zeta valence quality for $\mathrm{H}$ to Rn: Design and assessment of accuracy. Phys. Chem.

Chem. Phys. 2005, 7, 3297-3305.

(70) Andrae, D.; Haeussermann, U.; Dolg, M.; Stoll, H.; Preuss, H. Energy-adjusted ab initio pseudopotentials for the second and third row transition elements. Theor. Chim. Acta 1990, 77, $123-141$.

(71) Fóller J.; Marian, C.M. Rotationally Assisted Spin-State Inversion in Carbene-MetalAmides Is an Artifact. J. Phys. Chem. Lett. 2017, 8, 5643-5647.

(72) Thompson, S.; Eng, J.; Penfold T.J. The intersystem crossing of a cyclic (alkyl)(amino) carbene gold(I) complex. J. Chem. Phys. 2018, 149, 014304.

(73) Di, D.; Yang, L.; Richter J. M.; Meraldi, L.; Altamimi, R. M.; Alyamani, A. Y.; Credgington, D.; Musselman, K. P.; MacManus-Driscoll, J. L.; Friend, R. H. Efficient Triplet Exciton Fusion in Molecularly Doped Polymer Light-Emitting Diodes. Adv. Mater. 2017, 29, 1605987.

(74) Albrecht, K.; Matsuoka, K.; Fujita, K.; Yamamoto, K. A dendrimer emitter doped in a dendrimer host: efficient thermally activated delayed fluorescence OLEDs with fully-solution processed organic-layers. Mater. Chem. Front., 2018, 2, 1097-1103. 